OPEN ACCESS

Edited by:

Feng Wang,

City University of Hong Kong,

Hong Kong

Reviewed by:

Qianqian Su,

Shanghai University, China

Xiaomin $\mathrm{Li}$,

Fudan University, China

*Correspondence:

Khalid Uma

khalidumar4@gmail.com

Mohamad Nasir Mohamad Ibrahim mnm@usm.my

Specialty section:

This article was submitted to Nanoscience,

a section of the journa

Frontiers in Chemistry

Received: 21 January 2020

Accepted: 01 April 2020

Published: 19 May 2020

Citation:

Yaqoob AA, Ahmad H, Parveen T,

Ahmad A, Oves M, Ismail IMI,

Qari HA, Umar K and Mohamad Ibrahim MN (2020) Recent Advances in Metal Decorated Nanomaterials and

Their Various Biological Applications:

A Review. Front. Chem. 8:341.

doi: 10.3389/fchem.2020.00341

\section{Recent Advances in Metal Decorated Nanomaterials and Their Various Biological Applications: A Review}

\author{
Asim Ali Yaqoob ${ }^{1}$, Hilal Ahmad ${ }^{2}$, Tabassum Parveen ${ }^{3}$, Akil Ahmad ${ }^{4}$, Mohammad Oves ${ }^{5}$, \\ Iqbal M. I. Ismail ${ }^{5,6}$, Huda A. Qari ${ }^{5,7}$, Khalid Umar ${ }^{1 *}$ and \\ Mohamad Nasir Mohamad Ibrahim ${ }^{1 *}$ \\ ${ }^{1}$ School of Chemical Sciences, Universiti Sains Malaysia, Pulau Pinang, Malaysia, ${ }^{2}$ Centre for Nanoscience and \\ Nanotechnology, Jamia Millia Islamia, New Delhi, India, ${ }^{3}$ Department of Botany, Aligarh Muslim University, Aligarh, India, \\ ${ }^{4}$ School of Industrial Technology, Universiti Sains Malaysia, Pulau Pinang, Malaysia, ${ }^{5}$ Center of Excellence in Environmental \\ Studies, King Abdulaziz University, Jeddah, Saudi Arabia, ${ }^{6}$ Department of Chemistry, King Abdulaziz University, Jeddah, \\ Saudi Arabia, ${ }^{7}$ Department of Biological Science, King Abdulaziz University, Jeddah, Saudi Arabia
}

Nanoparticles (nanoparticles) have received much attention in biological application because of their unique physicochemical properties. The metal- and metal oxide-supported nanomaterials have shown significant therapeutic effect in medical science. The mechanisms related to the interaction of nanoparticles with animal and plant cells can be used to establish its significant role and to improve their activity in health and medical applications. Various attempts have been made to discuss the antibiotic resistance and antimicrobial activity of metal-supported nanoparticles. Despite all these developments, there is still a need to investigate their performance to overcome modern challenges. In this regard, the present review examines the role of various types of metal-supported nanomaterials in different areas such as antibacterial, antifungal, anticancer, and so on. Based on the significant ongoing research and applications, it is expected that metal-supported nanomaterials play an outstanding role not only in medical but also in other important areas.

Keywords: nanomaterials, metal oxide, biological application, therapeutics, tissue engineering

\section{INTRODUCTION}

Nanomaterials have found its way into different fields such as energy, environment, food industry, medicine, and so on (Mir et al., 2013; Khan et al., 2015; Sultana et al., 2015; Umar et al., 2016). Nanomaterials are still garnering attention at the scientific and commercial level (Xue et al., 2019). The properties of nanomaterials were found to be size-dependent, and this contributed to valuable chemical and physical properties. Recent developments have resulted in the improvement in the modeling and designing of different medical and biological tools and applications (Rathore et al., 2019; Yaqoob et al., 2019). The nanotechnology has garnered important commercial exploitation in the modern world. Nanomaterials have unique properties due to their small dimensions $(1-100 \mathrm{~nm})$. They have high electrical properties, high mechanical and thermal stability, high surface area, and high optical and magnetic properties (Khoshnevisan et al., 2019; Yaqoob et al., 2020a). These enhanced properties have enabled nanomaterials to be used in different fields including electrical, magnetic, optical, and electronic devices. Furthermore, some nanomaterials are engineered such as the modification occurring in case of titanium oxide, silver oxide, copper, 
zinc, and so on, with some other materials. Some of them are also found in different commercial production zones, such as production of sunscreens and stain-resistant clothing, and also used for investigative purposes in pharmaceuticals, diagnostic kits, imaging, magnetic resonance imaging (MRI), drug delivery, and in many more medical equipment and procedures (DaRocha et al., 2019; Ferreira et al., 2019; Silva and Rocha, 2019).

The nanomaterials that play a vital role in different applications in medical science commonly occur in some basic forms as shown in Figure 1. The first category of nanomaterial comprises the pure form of metal-based nanoparticles, which are also called metal nanoparticles (e.g., silver, copper, gold, titanium, platinum, zinc, magnesium, iron, and alginate nanoparticles). The other types of nanomaterials are the metal oxide nanoparticles (nanoparticles), that is, titanium dioxide, silver oxide, zinc oxide, and so on. The doped metal/metal oxide/metal nanomaterials are considered as another type of class among nanomaterials (Dar et al., 2011; Umar et al., 2013). Moreover, metal sulfide and metal organic frameworks (MOFs) nanomaterials have also concerned excellent interest because of their promising properties and applications in different biological fields. For example, AgS, CuS, FeS nanoparticles, $\mathrm{Zn}$-based MOF, Cu-based, Mn-based MOF, and so on, are very commonly used in various medical applications such as drug delivery and antimicrobial activities.

Based on the nano concept, nanomedicine is also gaining more attention by making better diagnosis and developing different ways of treatment using nanoparticles in many diagnostic devices (Banerjee, 2018; Gurav et al., 2019; Ouyang et al., 2019). The noble metal nanoparticles (Ag, Au, Pt) have also attracted significant interest due to their photothermal and optical properties (Yaqoob et al., 2020b). These metal nanoparticles exhibit resonance electron oscillation known as localized surface plasmon resonance (Khan et al., 2017). The ability to integrate the noble metal nanoparticles into biological system with nontoxicity has impacted significantly medicinal and biological research. Among noble metallic nanoparticles, the gold nanoparticles got much attention due to its distinctive low toxicity, ease of preparation, and favorable attachment with biological molecules (Elahi et al., 2018).

The silver nanoparticles have been proven to be most useful because they have excellent antimicrobial properties against lethal viruses, microbes/germs, and other nucleus containing microorganisms. These nanoparticles are certainly the most extensively utilized material among all. Thus, it has been used as antimicrobial agent in different textile industries (Hasan, 2015). The noble metal nanoparticles are considered as more specific and multipurpose agents with a diversity of biomedical applications considering their use in extremely sensitive investigative assays, radiotherapy enhancement, gene delivery, thermal ablation, and drug delivery. These metallic nanoparticles are also considered to be nontoxic by the scientific community in case of gene and drug delivery applications. Moreover, metallic nanoparticles can offer diagnostic and therapeutic possibilities simultaneous (Yamada et al., 2015). Ceramics are another class of metal oxide nanoparticles that is currently emerging as antimicrobial agents for diagnostic purpose, in drug delivery devices, and agent in different pharmaceutical and medical treatments.

Some metal oxides also show antimicrobial activities, such as $\mathrm{TiO}_{2}, \mathrm{Bi}_{2} \mathrm{O}_{3}, \mathrm{ZnO}, \mathrm{FeO}, \mathrm{MnO}_{2}, \mathrm{CuO}, \mathrm{Ag}_{2} \mathrm{O}, \mathrm{Al}_{2} \mathrm{O}_{3}$, and so on, and play significant roles in various medical applications. For example, $\mathrm{TiO}_{2}$ has been used against the transmission of different infectious diseases (Janson et al., 2019; Mora et al., 2019).

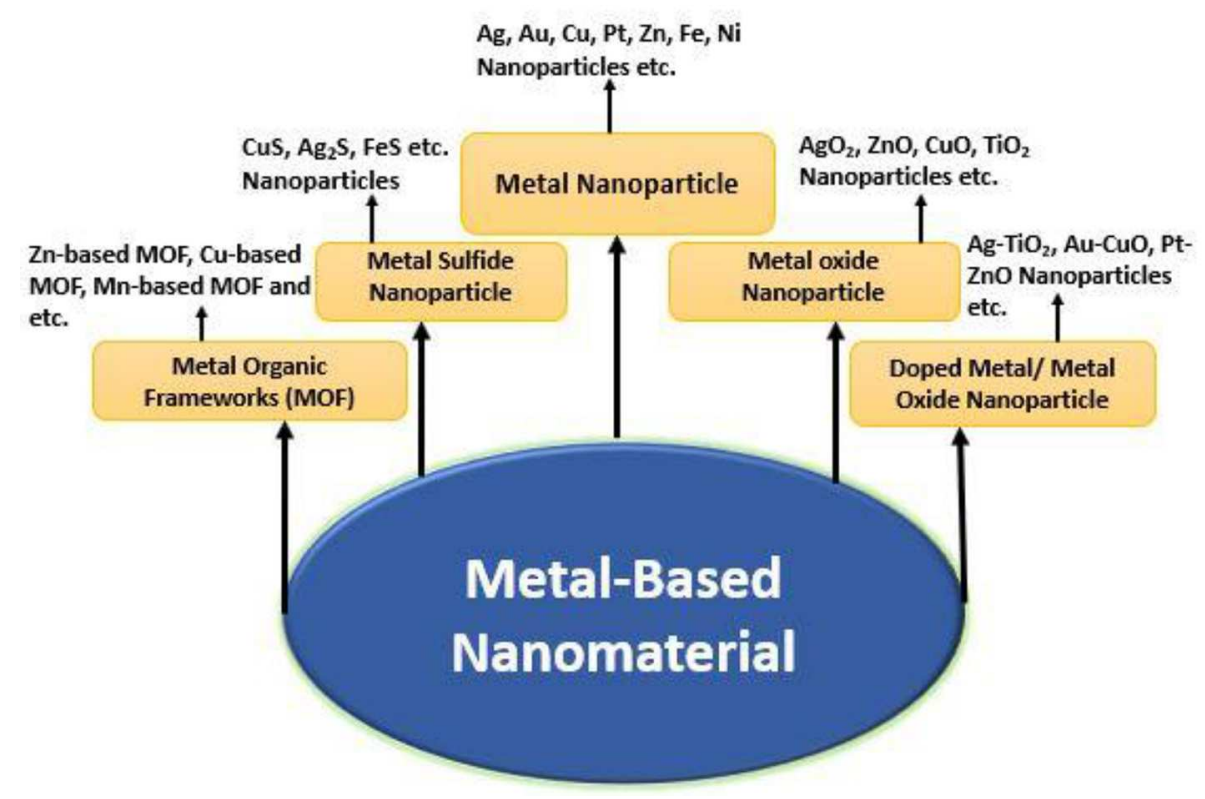

FIGURE 1 | Different types of metal-based nanomaterials. 
Similarly, $\mathrm{ZnO}$ nanoparticles are gaining worldwide attention due to their antibacterial activity. Zinc oxide is considered a biosafe material, and it is used to carry out photocatalysis and photo-oxidation reactions on biological and chemical species (Sirelkhatim et al., 2015). Moreover, $\mathrm{Al}_{2} \mathrm{O}_{3}$ nanoparticles have enormous viable applications and showed antimicrobial behavior (Swaminathan and Sharma, 2019). Sankar et al. (2014) reported that the $\mathrm{CuO}$ complex of Ficus religiosa nanoparticles was used as an anticancer agent in biomedicine because of its excellent chemical properties. The zinc-doped titania nanoparticles have revealed enhanced proangiogenic properties, which might be useful in different applications (Hadi et al., 2018). In another study, doped copper/ $/ \mathrm{TiO}_{2}$ nanoparticles with carbon-based allotrope such as graphene oxide were reported as a new antimicrobial agent. The $\mathrm{CuO}$ has been utilized as an antimicrobial agent to degrade various microbial species (Nethi et al., 2017).

However, (Shivashankarappa and Sanjay, 2015) studied the biological approaches for the synthesis of cadmium sulfide (CdS) nanoparticles and used as antimicrobial agent against the diet borne pathogens. The antimicrobial activity results showed that the CdS nanoparticles have the highest zone of inhibition in case of Aspergillus flavus and Pseudomonas aeruginosa. Recently, (Aishwarya and Sanjay, 2020) studied the green synthesis of CdS nanoparticles from Escherichia coli and analyzed their toxic effect on cancer therapy. Antimicrobial studies of $\mathrm{CdS}$ nanoparticles were also done on the food basis pathogens, and toxicity was determined on musculus skin melanoma (B16F10) and humanoid epidermoid carcinoma (A431) cell appearance. So, CdS nanoparticles were found to be extremely active on cancerous cells as compared to normal anticancer drugs. Cai et al. (2019) studied the stimuli-responsive nanomaterials due to rapid growth of nanotechnology, which provided an alternate way for the designing of well-behaved drug delivery schemes due to their spatiotemporally wellbehaved properties. Furthermore, the MOFs have also been broadly employed in medical applications, particularly in drug delivery, due to tunable hole size, large surface area and high pore volume, and informal surface variation. The main aim of this review is to explore the importance of metalbased nanomaterials (such as metal nanoparticles, metal oxide nanoparticles, doped metal/metal/metal-oxide, metal sulfide, and MOF) for their effective applications in biomedicine. This review also considers the role of nanoparticles in biology reported by many researchers along with their potential applications. Finally, a brief discussion is made to indicate the future perspectives of metallic nanomaterials.

\section{ROLE OF NANOPARTICLES}

Antibiotic-resistant pathogens have become a serious threat to human health. Among them, pathogenic microbes such as Geobacter, Staphylococcus, Enterococcus, and Streptococcus are responsible for various serious diseases and infections (Olishevska et al., 2019). These bacterial infections and diseases may lead to death of the affected individual at severe stage.
New strategies are needed to prepare the advance level drugs or antibiotics to control these bacterial infections. Recently, nanotechnology has provided a great potential in several area of engineering, environmental science, medical science, and other fields.

Recently, the different types of metallic nanoparticles and their derivatives (such as silver, gold, copper, nickel, platinum, titanium, and zinc nanoparticles) received significant attention for their effective antimicrobial properties. Similarly, metal oxides and doped metal/metal composites such as silver oxide, copper oxide, calcium oxide, magnesium oxide, titanium dioxide, and zinc oxide have various unique properties, powerful potencies, and spectral activity and showed excellent antimicrobial ability (Dizaj et al., 2014). Furthermore, the physicochemical properties and morphology of nanomaterials have been proven for their antimicrobial activities. It was identified that the nano size metal particles carry the powerful bactericidal effect to resist the bacteria (Mohammadi et al., 2011; Fellahi et al., 2013; Besinis et al., 2014). The positive charge on the surface of metallic nanoparticles enables their binding ability toward negative charged bacteria surface, which may increase the bactericidal effect. The shape of the nanoparticle is also a very important factor because it also has a strong influence on the antimicrobial activity (Bera et al., 2014).

\section{Metal-Based Nanoparticles}

The metal-based nanoparticles such as silver, gold, copper, iron, zinc, platinum, and so on, received much attention in medicine. Faraday (1857) showed the metal nanoparticles can exist in solution. Much later, Kumar et al. (2018) studied the color and morphology of metallic nanoparticles. Currently, nanoparticles can be synthesized and improved by modifying the chemical groups, which help to bind the antibodies. Noble metal nanoparticles ( $\mathrm{Ag}, \mathrm{Au}, \mathrm{Pt}$ ) have been used for several biomedical applications such as anticancer, radiotherapy enhancement, drug delivery, thermal ablation, antibacterial, diagnostic assays, antifungal, gene delivery, and many others. The noble metal nanoparticles have some unique properties that make it more valuable. Metal nanoparticles can be functionalized with a variety of functional groups, such as peptides, antibodies, RNA, and DNA, to target different cells along with potential biocompatible polymers, for example, polyethylene glycol (Fan et al., 2018). Some important nanoparticles along with their biological applications to target biological cells are summarized in Table 1.

Xiong et al. (2011) synthesized copper nanoparticles with less than $2 \mathrm{~nm}$ particle size by using L-ascorbic acid. It was used as a stabilizer and as a reducing agent. These nanoparticles were used as an efficient antibacterial agent against gram-negative and gram-positive bacteria. (Tomar and Garg, 2013) prepared the $\mathrm{Au}$ nanoparticles for identification of protein interactions and used it in the detection and evaluation of DNA from biological samples. Gold nanoparticles have been used as a detector in aminoglycoside antibiotics, to identify the cancer cells, and also it was found useful in identification of different microorganisms. Dreaden et al. (2012) used Au nanoparticles in cancer diagnosis and its imaging through transporting the nanoparticles into 
TABLE 1 | Different metal nanoparticles with their potential applications.

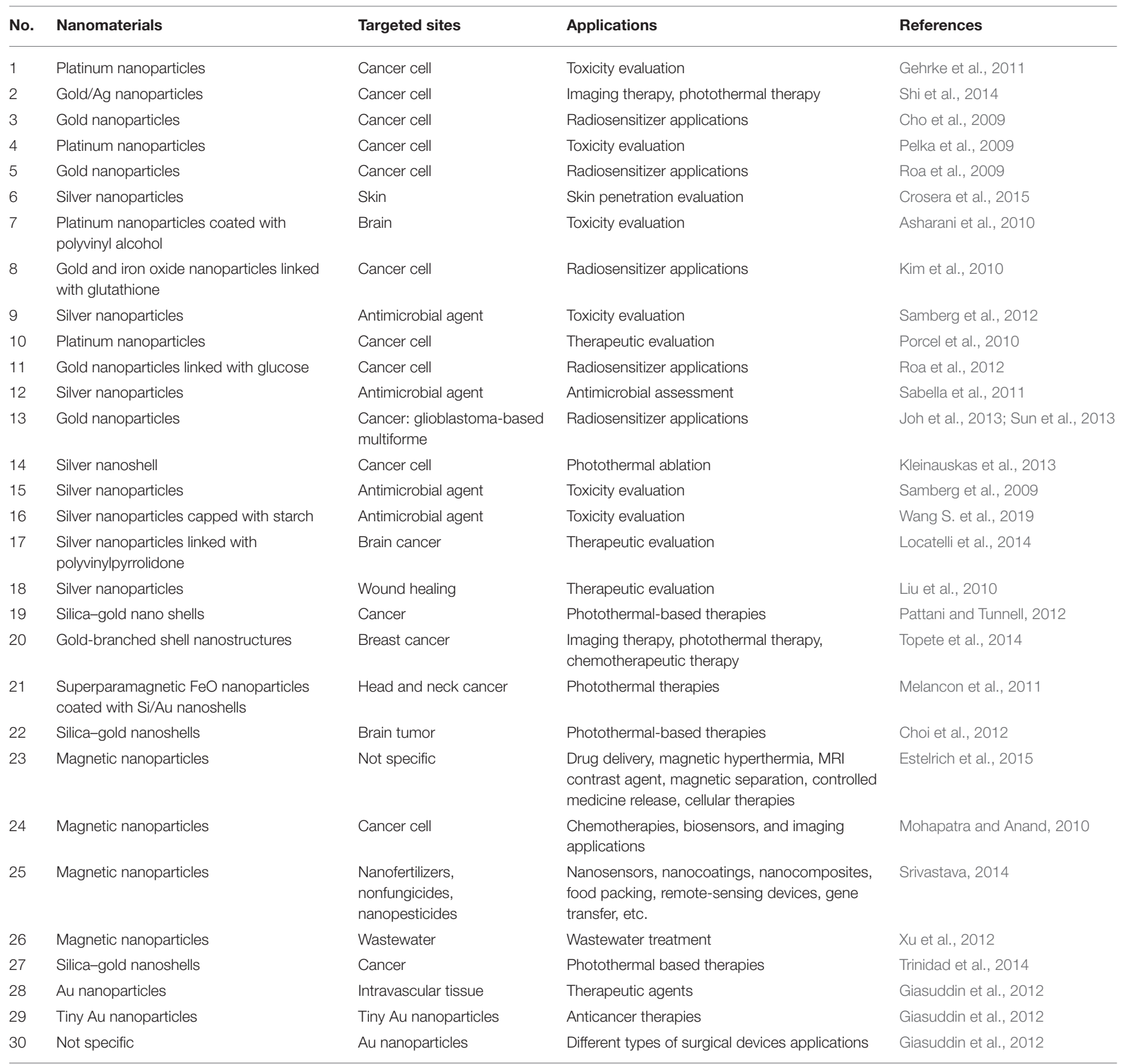

targeted cell nucleus. This highlighted the role of nanoparticles in different biomedicine applications.

The health care industries are facing challenges due to antimicrobial resistance by pathogenic bacteria. Rai et al. (2009) studied the Ag nanoparticles and checked the combined effect with antimicrobial activities. The antimicrobial activity of amoxicillin, penicillin G, clindamycin, vancomycin, and erythromycin were found to be improved owing to the presence of $\mathrm{Ag}$ nanoparticles against the strains. Keat et al. (2015) elaborated the role of $\mathrm{Ag}$ nanoparticles in biomedicine to serve as cell imaging, cancer therapy, genetic delivery, drug delivery, and different disease diagnosis. Ag nanoparticles have greatly influenced the medical practice, as well as the health care unit. Fellahi et al. (2013) observed the antibacterial activities of silicon nano substrates linked with $\mathrm{Ag}$ nanoparticles or $\mathrm{Cu}$ nanoparticles. Their study concluded that the synthesized nanoparticles have improved antibacterial activities against $E$. coli. The Ag-coated silicon wires were biocompatible with regard to the human lung, especially adenocarcinoma epithelial cells, whereas the $\mathrm{Cu}$-coated $\mathrm{Si}$ nanowires exhibited high cytotoxicity that may lead to death. Siddiqi and Husen (2017) studied the medical applications of $\mathrm{Pd}$ nanoparticles and tried to make 
them more prolific. Pd nanoparticles can act as anticancer and stabilizing agents in many pharmaceutical products.

\section{Metal Oxide-Based Nanoparticle}

The role of metal oxide nanomaterials has been studied with excellent results in biomedicine. Metal oxide nanoparticles such as $\mathrm{Ag}_{2} \mathrm{O}, \mathrm{FeO}, \mathrm{MnO}_{2}, \mathrm{CuO}, \mathrm{Bi}_{2} \mathrm{O}_{3}, \mathrm{ZnO}, \mathrm{MgO}, \mathrm{TiO}_{2}$, $\mathrm{CaO}, \mathrm{Al}_{2} \mathrm{O}_{3}$, and many others were acknowledged to show potential antibacterial activity. Some reported metal oxides used in biomedical application are listed in Table 2.

Sathyanarayanan et al. (2013) studied the impact of $\mathrm{Ag}_{2} \mathrm{O}$ nanoparticles and considered it as a novel source of antibiotics. Furthermore, Salas et al. (2019) also demonstrated the antimicrobial properties of $\mathrm{Ag}_{2} \mathrm{O}$ nanoparticles against $E$. coli. The $\mathrm{ZnO}$ nanoparticles exhibited good bactericidal effects against the gram-positive and gram-negative microorganisms and spores. These microorganisms and spores are not affected by high pressure and temperature. Moreover, Prasanna et al. (2019) explored the antibacterial activities of $\mathrm{ZnO}$ with different particle sizes. From the results, it was proved that the bactericidal efficacy of $\mathrm{ZnO}$ nanoparticles increased as the particle size decreased. Azam et al. (2012) studied the relative antimicrobial activities of $\mathrm{CuO}, \mathrm{ZnO}$, and $\mathrm{Fe}_{2} \mathrm{O}_{3}$ nanoparticles effect on gram-negative bacteria, such as E. coli, $P$. aeruginosa, and so on, and gram-positive bacteria, such as Staphylococcus aureus and Bacillus subtilis. From these results, $\mathrm{ZnO}$ was found to have a good antimicrobial activity, whereas $\mathrm{Fe}_{2} \mathrm{O}_{3}$ nanoparticles showed the least antibacterial effect.

The antibacterial activity of $\mathrm{TiO}_{2}$ nanoparticles is associated to its crystal structure and its morphology, such as size, shape, and so on. Roy et al. (2010) discussed the $\mathrm{TiO}_{2}$ nanoparticles effect with diverse antiagents against methicillin-resistant $S$. aureus. $\mathrm{TiO}_{2}$ nanoparticles enhanced the antimicroorganism effect of $\beta$-glycopeptides, lactums, macrolids, cephalosporins, aminoglycosides, and tetracycline against methicillin-resistant $S$. aureus. Haghighi et al. (2013) studied the antifungal effect of $\mathrm{TiO}_{2}$ nanoparticles on biofilm of fungus. The results demonstrated that the synthesized $\mathrm{TiO}_{2}$ nanoparticles had enhanced antifungal properties on Candida albicans biofilms. The authors also suggested that $\mathrm{TiO}_{2}$ nanoparticles could efficiently hinder the fungal growth on biofilms, particularly those produced on medical devices. Another challenge of $\mathrm{TiO}_{2}$ nanoparticles is its toxicity, but the doping and conjugation with nontoxic material were used and proved to be a very novel approach. Similarly, $\mathrm{MnO}_{2}, \mathrm{Bi}_{2} \mathrm{O}_{3}$, and $\mathrm{FeO}$ got significant attraction in the field of biomedical such as drug delivery, bioimaging, antimicrobial activities, and many more. For example, Wang Y. et al. (2017) reported the preparation of bovine serum albuminfunctionalized $\mathrm{FeO}$ nanoparticles $(4.8 \mathrm{~nm})$ with higher relativity value, that is, $444.56 \mathrm{mM}^{-1} \mathrm{~s}^{-1}$, which can serve as in vivo bioimaging of tumor cells. Similarly, in another study, Gao et al. (2018) introduced a theranostic-based nanocomposite with multiscale $\mathrm{FeO}$ nanoparticles for magnetic resonance bioimaging and chemotherapy for treatment of breast cancer. Similarly, $\mathrm{MnO}_{2}$ is considered as an ideal compound because of having remarkable physicochemical, structural, and morphology-based properties. The remarkable 2D planar structure and of $\mathrm{MnO}_{2}$ nanoparticles are very significant for medical applications (Wu et al., 2019). Chen et al. (2019) studied the $\mathrm{MnO}_{2}$ nanosheets and explored it for various applications such as biological imaging, biosensing, cancer therapy, molecular adsorption, and drug delivery. The outcomes showed that the $\mathrm{MnO}_{2}$ nanosheets show less cytotoxicity and higher hemo/histocompatibility. Ovsyannikov et al. (2015) synthesized

TABLE 2 | Role of different metal oxides in biomedical field.

\begin{tabular}{|c|c|c|c|}
\hline Sr no. & Nanomaterial & Applications & References \\
\hline 2 & Silver oxide & Antimicrobial, drug delivery, gene therapies, tissue developments, imaging, etc. & Shanmuganathan et al., 2019 \\
\hline 4 & Silica oxide & $\begin{array}{l}\text { Production of thermal and electric insulators gene delivery, catalyst applications, drug carriers, } \\
\text { efficient adsorbents, serve as filler materials, etc. }\end{array}$ & Schrand et al., 2010 \\
\hline 5 & Zinc oxide & Skin protectant, etc. & Pantic et al., 2019 \\
\hline 7 & Nickel (oxide) & Biomedical applications such as anticancer & Khan et al., 2019 \\
\hline 8 & Copper oxide & $\begin{array}{l}\text { CuO can work as, antibiotic, antiviral, antimicrobial, antifouling, and antifungal treatment and } \\
\text { many other nonmedical applications such as inks, coating materials, catalyst factor, lubricants, } \\
\text { filler substance for enhanced wear resistance and conductivity }\end{array}$ & Schrand et al., 2010 \\
\hline 9 & Gold oxide & $\begin{array}{l}\text { Antimicrobial, drug delivery, cellular imaging, photodynamic therapies, cancer treatment, } \\
\text { surgical devices, etc. }\end{array}$ & Schrand et al., 2010 \\
\hline 13 & Magnesium oxide & Antibacterial applications & Dizaj et al., 2014 \\
\hline 14 & Bismuth oxide & Drugs delivery systems & Szostak et al., 2019 \\
\hline 15 & Chromium oxide & Used in improving collagen stability & Sangeetha et al., 2012 \\
\hline 16 & Manganese dioxide & Biocatalysis, fluorescence sensing, controlled drug delivery, stimuli-activated imaging & Wu et al., 2019 \\
\hline
\end{tabular}


the spherical $\mathrm{Bi}_{2} \mathrm{O}_{3}$ nanoparticles $(35 \mathrm{~nm})$ and used as cancer cell aggressive agent. It was recommended to use a mixture of achieved nanospheres with phenothiazine photosensitizer, which showed drug delivery properties. Szostak et al. (2019) studied the $\mathrm{Bi}_{2} \mathrm{O}_{3}$ nanoparticles and successfully used as drug carrier in medical field. Ahamed et al. (2014) revealed that the $\mathrm{CuO}$ nanoparticles had substantial antimicrobial properties against different bacterial strains such as Proteus vulgaris, E. coli, Klebsiella pneumoniae, Shigella flexneri, P. aeruginosa, Enterococcus faecalis, Salmonella typhimurium, and S. aureus. Among these, E. faecalis and E. coli presented maximum sensitivity to $\mathrm{CuO}$ nanoparticles, whereas $K$. pneumoniae was unaffected by the nano formulations. The $\mathrm{CaO}$ nanoparticles and $\mathrm{MgO}$ nanoparticles show good antibacterial activities in an alkaline environment and oxygen. Leung et al. (2014) synthesized the $\mathrm{MgO}$ nanoparticles and studied its antibacterial activities. They showed that the route may be due to damage of the cell membrane. The $\mathrm{MgO}$ nanoparticles was shown to have antimicrobial effect on gram-positive and gram-negative bacteria. Leung et al. (2016) studied the antibacterial properties of $\mathrm{MgO}$ nanoparticles against $E$. coli and $S$. aureus. The authors recommended that the active oxygen on $\mathrm{MgO}$ nanoparticles was key the factor contributing to the bacterial activities. The $\mathrm{MgO}$ and $\mathrm{CaO}$ nanoparticles show excellent antibacterial properties. It can be prepared at low cost with easily available materials and have excellent biocompatibility. These materials can also be used in food processing and environmental preservation besides their biomedical uses.

\section{Doped Metal/Metal/Metal Oxide-Based Nanoparticles}

Researchers are now focusing on the modification of nanomaterial to make it more stable during the chemical processing and to make the materials safe for the ecosystem. The doped metal/metal and metal/metal oxide nanoparticles are known to lead to enhanced efficiency in the biomedical applications of metal oxides along with their major outcomes. These are summarized in Table 3.

The $\mathrm{ZnO}$ doped with $\mathrm{Sb}$ or $\mathrm{Mg}$ may increase the antibacterial activities of $\mathrm{ZnO}$ nanoparticles. The doped metallic nanoparticles were recommended to be used in different applications in pharmaceuticals because it has less self-toxicity issues. Guo et al. (2015) studied the antimicrobial effect of tantalum-doped zinc oxide nanoparticles on numerous microbes of gram-positive bacteria such as B. subtilis, S. aureus, and gram-negative E. coli and $P$. aeruginosa. The Ta- and $\mathrm{ZnO}$-doped nanoparticles showed more active antimicrobial capability than $\mathrm{ZnO}$ nanoparticles in ambient darkness. It increased the surface bioactivities and enhanced the electrostatic force due to the combination of $\mathrm{Ta}^{5+}$ ions with $\mathrm{ZnO}$ nanoparticles. The results revealed enhancement in antibacterial activities by using $5 \%$ doped nanoparticles than other pure metal oxide nanoparticles.

Malka et al. (2013) synthesized the $\mathrm{Zn}$-doped $\mathrm{CuO}$ and deposited in on the surface of cotton fabric through ultrasound irradiation. A colloidal suspension of $\mathrm{Zn}$-doped $\mathrm{CuO}$ was used to deposit on the surface of the cotton fabric. The antimicrobial activities of this treated fabric were used against gram-negative and gram-positive bacteria. A significant improvement of 10,000 times was observed in the antibacterial activity of $\mathrm{Zn}-\mathrm{CuO}-$ doped nanoparticles compared to pure $\mathrm{CuO}$ nanoparticles and $\mathrm{ZnO}$ nanoparticles. Rekha et al. (2010) used doped $\mathrm{Mn} / \mathrm{ZnO}$ nanoparticles to study the photocatalytic and antibacterial activity. The effect of $\mathrm{Mn}$ doping was studied with respect to doping concentration, its structural morphology, and optical properties. The results showed that $\mathrm{Mn} / \mathrm{ZnO}$ nanoparticles increased the antibacterial activities compared to the metal oxide ( $\mathrm{ZnO})$ nanoparticles.

Dhanasekar et al. (2018) introduced the $\mathrm{Cu}$-doped $\mathrm{TiO}_{2}$ nanoparticles in the presence of reduced graphene oxide (rGO), which served as the solid support. It was then used as an innovative light antibacterial agent. The results suggested that the nanoparticles of $\mathrm{Cu}_{2} \mathrm{O}-\mathrm{TiO}_{2}$ in the presence of $\mathrm{rGO}$ showed improved visible light antimicroorganism properties with advanced inhibition zone and lesser value of least inhibitory concentration for gram-positive and gram-negative microorganisms as compared to pure $\mathrm{TiO}_{2}$.

Llorens et al. (2012) stated that Ag-doped $\mathrm{MgO}$ showed significant important antimicrobial activities in biomedical applications. Nganga et al. (2013) elaborated the Ag polysaccharide doping with fiber reinforcement composites. It was exposed for antimicrobial activities against $S$. aureus and $P$. aeruginosa. The Ag-fiber reinforcement composites presented excellent antimicrobial efficiency against microbial strains. Arakawa et al. (2019) studied the antimicrobial activity of Ag and carbon monolith doped nanoparticles. Carbon monolith with Ag doping also showed improved antimicrobial efficiency against C. albicans, S. aureus, and E. coli. Furthermore, Ag doped with phosphate-based glasses was investigated by Zhu et al. (2019) to explore the antimicrobial activities through disk diffusion analyses against certain disease-causing pathogens such as $S$. aureus, E. coli, Bacillus cereus, P. aeruginosa, and so on. Ewald et al. (2011) used the Ag from cements against S. aureus and Staphylococcus epidermidis growth. The results showed excellent antibacterial properties.

\section{Metal Sulfide-Based Nanoparticles}

Metal-based chalcogenides are considered as the most promising semiconductor resource with many medical applications due to the presence of definite properties at nanometric levels. The included properties are high fluorescence; fine optical band gap; and excellent magnetic, thermal, mechanical, and structural stability (Vena et al., 2016). Furthermore, Quantum dots, nanocrystals, and metal-based chalcogenide nanoparticles have been projected for biomaterials in biosensor, drug delivery, biolabeling, bioimaging, and diagnostic purpose. There are some metal-based chalcogenides such as CdSe, PbS, CdSe-CdTe, CdSe$\mathrm{ZnTe}$, CdTe-CdSe, and so on, which have very complex structures (Li and Wong, 2017). Recently, metallic sulfides that contain chalcogenide sulfur are significantly bonded with a toxic-free metal, and they obtained much interest in the medical field (Dahoumane et al., 2016). Among them, the most common metal sulfides are AgS, CuS, FeS, and $\mathrm{ZnS}$ and are considered as the most important materials for biomedical applications. 
TABLE 3 | Doped nanomaterials with their major outcomes.

\begin{tabular}{|c|c|c|c|c|c|}
\hline S. no. & Nanomaterial & Dopant & Application & Major outcomes & References \\
\hline 1 & $\mathrm{ZnO}$ & Co & Antimicrobial activity & $\begin{array}{l}\text { ZnO doped with Co nanoparticles was identified to } \\
\text { be crystalline with a single phase } \\
\text { - It increased crystallite size from } 20.5 \mathrm{~nm} \text { to } \\
25.7 \mathrm{~nm} \\
\text { - Doping enhanced the antibacterial activities of } \\
\text { composite to control marine borne pathogen }\end{array}$ & Oves et al., 2015 \\
\hline 2 & $\mathrm{ZnO}$ & $\mathrm{TiO}_{2}$ & $\begin{array}{l}\text { Water decontamination } \\
\text { applications, angiogenic } \\
\text { applications }\end{array}$ & $\begin{array}{l}\text { - Doped composite is found good agents for } \\
\text { multifunctional environmental applications } \\
\text { - Zn-doped titania nanoparticles composite have } \\
\text { exposed enhanced proangiogenic properties }\end{array}$ & Nethi et al., 2017 \\
\hline 3 & $\mathrm{Fe}_{3} \mathrm{O}_{4}$ & Gelatin & $\begin{array}{l}\text { Drug delivery, MRI, different } \\
\text { therapies, fluorescence sensor, } \\
\text { etc. }\end{array}$ & $\begin{array}{l}\text { - Enhanced the biomedical application efficiency in } \\
\text { different zones }\end{array}$ & Cheng et al., 2014 \\
\hline 4 & Polycrystalline ZnO & $\mathrm{Mn}$ & Antimicrobial activity & $\begin{array}{l}\text { - Result demonstrated that the Mn-doped ZnO } \\
\text { nanoparticles increased antibacterial activities } \\
\text { than pure ZnO nanoparticles }\end{array}$ & Rekha et al., 2010 \\
\hline 5 & $\mathrm{Ag}$ & $\mathrm{Zn}$ & Antimicrobial applications & $\begin{array}{l}\text { - Doped composite enhances the performance } \\
\text { against } E \text {. coli and Vibriocholerae }\end{array}$ & Salem et al., 2015 \\
\hline 6 & $\mathrm{TiO}_{2}$ & $\begin{array}{l}\text { ZnO/graphene } \\
\text { oxide }\end{array}$ & Drug delivery & $\begin{array}{l}\text { - They showed the substantial toxicity; due to this, } \\
\text { the cell viability condensed }\end{array}$ & Zamani et al., 2018 \\
\hline 7 & $\mathrm{ZnO}$ & $\mathrm{Fe}$ & $\begin{array}{l}\text { Cytotoxicity screening } \\
\text { applications }\end{array}$ & $\begin{array}{l}\text { - This doping used to enhance the nanosafety by } \\
\text { reducing ZnO through doping }\end{array}$ & George et al., 2009 \\
\hline 8 & $\mathrm{ZnO}$ & $\mathrm{Ta}$ & Antibacterial applications & $\begin{array}{l}\text { Ta-doped ZnO nanoparticles composite showed } \\
\text { more active bactericidal value than pure } \mathrm{ZnO} \text { in } \\
\text { presence of dark ambient and improved the } \\
\text { synergistic effect with surface bioactivity }\end{array}$ & Guo et al., 2015 \\
\hline 9 & $\mathrm{ZnO}$ & $\mathrm{TiO}_{2}$ & Biomedical applications & $\begin{array}{l}\text { - The results showed that the nanoparticles } \\
\text { composite can be genotoxic without being } \\
\text { cytotoxic }\end{array}$ & Osman et al., 2010 \\
\hline 10 & $\mathrm{TiO}_{2}$ & $\begin{array}{l}\text { Reduced } \\
\text { graphene oxide }\end{array}$ & $\begin{array}{l}\text { Ambient light-based } \\
\text { antimicrobial activities }\end{array}$ & & Dhanasekar et al., 2018 \\
\hline 11 & $\mathrm{TiO}_{2}$ & $\mathrm{Cu}$ & $\begin{array}{l}\text { Ambient light-based } \\
\text { antimicrobial activities }\end{array}$ & $\begin{array}{l}\text { - Doping with } \mathrm{Cu} @ \mathrm{TiO}_{2} \text { promoted degradation of } \\
\text { different microorganisms }\end{array}$ & Dhanasekar et al., 2018 \\
\hline 12 & $\mathrm{Zn}$ & $\mathrm{CuO}$ & $\begin{array}{l}\text { Multidrug-resistant bacteria } \\
\text { applications }\end{array}$ & - Mechanism of antibacterial activity is enhanced & Malka et al., 2013 \\
\hline 13 & $\mathrm{TiO}_{2}$ & $\mathrm{Ag}_{2} \mathrm{O}$ & $\begin{array}{l}\text { Drug-resistant bacterial } \\
\text { applications }\end{array}$ & $\begin{array}{l}\text { - Doped material enhanced the resistant ability } \\
\text { against leishmania parasites }\end{array}$ & Allahverdiyev et al., 2011 \\
\hline 14 & Multiwalled CNT & $\mathrm{Ag}$ & Biomedical applications & - Used for cellular viability and cellular proliferation & Madhumitha et al., 2015 \\
\hline 15 & $\begin{array}{l}\text { Zirconium titanium } \\
\text { phosphate }\end{array}$ & $\mathrm{Ag}$ & Antibacterial applications & Found best antibacterial agent against $E$. coli & Biswal et al., 2011 \\
\hline
\end{tabular}

However, Goel et al. (2014) studied the CuS nanoparticles, which are progressively developing as a most promising stage for biosensing, photothermal therapy, biomolecular imaging, and drug deliveries. The CuS nanoparticles showed significant role in vitro and in vivo applications. CuS nanoparticles and their derivatives have been extensively used in molecules detection technology such as DNA detections, metabolites (glucose) detections, food-based pathogen, and so on. The growing popularity of $\mathrm{CuS}$ nanoparticles in the field of biosensing is primarily based on conductivity and capacity of these nanoparticles, which encourage electron transfer reactions with molecules. Furthermore, CuS thin filmbased immunosensor was introduced for the exposure of anthropological immunoglobulin A (IgA) antibody in serum, in which a goat antihuman IgA antimediator was immobilized on surface of CuS thin film (Attarde and Pandit, 2020). The functionalized quantum dots of $\mathrm{Ag}_{2} \mathrm{~S}$ are also important to use in bioimaging and diagnostics purposes. The imaging, labeling, tissue imaging, diagnosis, and photodynamic treatment are few bioapplications of $\mathrm{Ag}_{2} \mathrm{~S}$. Another stimulating application of $\mathrm{Ag}_{2} \mathrm{~S}$ quantum dots is tracking and designing of cells in vivo. Conventionally, proteins and dyes were considered as imaging tracking agent to achieve nanometer precision. Recent developments of metal sulfide-based nanoparticles (CuS nanoparticles) have covered an extensive variety of medical applications as shown in Figure 2.

The literature also showed that the $\mathrm{Ag}_{2} \mathrm{~S}$ quantum dots can be used as an excellent active tracker for human mesenchymal stem cells in vivo within a range of near-infrared (1,000-1,400 nm). $\mathrm{Ag}_{2} \mathrm{~S}$ nanoparticles were found as an excellent material to 


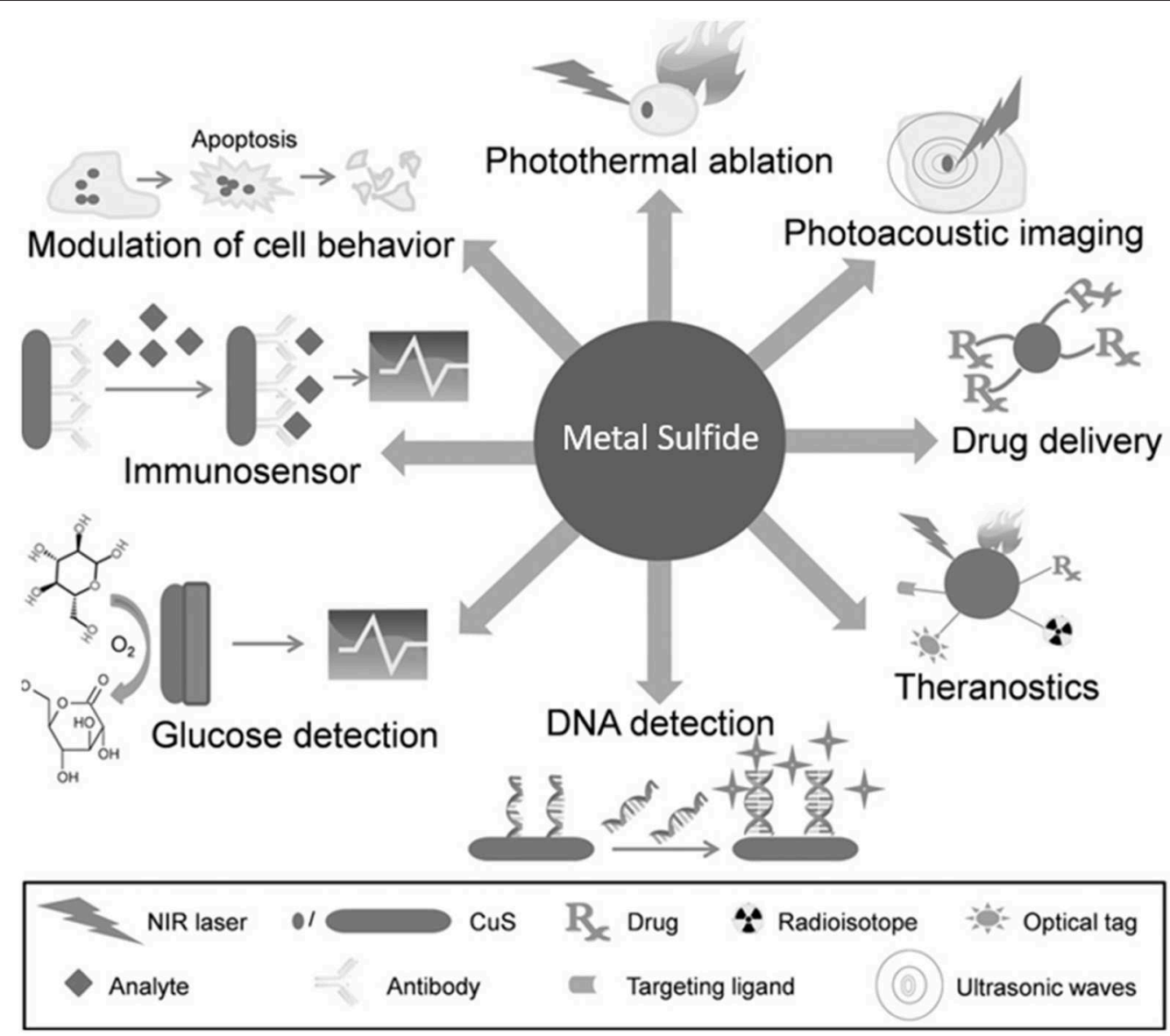

FIGURE 2 | Potential medical applications of metal Sulfide based nanoparticles (CuS nanoparticles). Adapted from Goel et al. (2014), with permission from (C) Wiley@vCH Verlag GmbH \& Co. K GaA, Weinheim.

demonstrate the microbial progress inhibition. This is also a perspective application of $\mathrm{Ag}_{2} \mathrm{~S}$ nanoparticles (Argueta-Figueroa et al., 2017). However, Kumari et al. (2014) found that the $\mathrm{Ag}_{2} \mathrm{~S}$ nanoparticles show a reasonable antimicrobial consequence too. The $\mathrm{Ag}_{2} \mathrm{~S}$ nanoparticles $(0.1 \mu \mathrm{g} / \mathrm{mL})$ treatment offered $75 \%$ growth inhibition rate against $E$. coli and $S$. aureus strains. Tian et al. (2011) reported the CuS nanoparticles as photothermal agents for the treatment of cancerous cells, although the $500 \mathrm{~nm}$ particle size limits their scientific version. Ding et al. (2016) synthesized the $\mathrm{Fe}_{3} \mathrm{~S}_{4}$ nanoparticles along with pseudoenzyme activities. These activities were applied to enterprise a measurable photometric enzyme glucose and assess in human serum, which leads to a final product from an enzyme material that is oxidized by hydrogen peroxide through $\mathrm{Fe}_{3} \mathrm{~S}_{4}$ nanoparticles. Similarly, Argueta-Figueroa et al. (2017) studied the $\mathrm{Ag}_{2} \mathrm{~S}, \mathrm{CuS}$, and FeS significant value in the field of biomedical. Moreover, the summary of metal sulfide nanoparticle and their biomedical applications are shown in Table 4.

\section{Metal Organic Frameworks}

Metal organic frameworks are also known as a comparatively novel crystalline nanoporous material. The MOFs are defined as the self-assembly of metallic ions that serve as coordination centers and organic/inorganic-based ligands, which serve as linkers in metallic centers as shown in Figure 3 (Keskin and Kizilel, 2011).

This is one of the most stimulating new expansions in nanoporous science, also known as porous coordination, hybrid organic-inorganic coordination networks. The MOFs have some unique properties that make it more prolific such as high porosity and high surface area, which are usually from 1,000 to $10,000 \mathrm{~m}^{2} / \mathrm{g}$, which is higher than conventional porous materials (Arenas-Vivo et al., 2019). Metal organic frameworks extensively explored for drug delivery system in modern development due to excellent drug-loading capacity, informal functionalization, ideal biodegradability, and good biocompatibility. Keskin and Kizilel (2011) regarded the MOFs as optimal material for drug delivery application due to modification of pore size and some prospect of regulating functional groups. The MOF significant generalized system as drug delivery is shown in Figure 4 along with in vivo conditions.

An et al. (2012) studied the Zn-based MOFs to load the drugs and discharge for immobilization of larger molecules. Bio-MOF100 named nanomaterial was effectively used for drug storage 
TABLE 4 | Summary of metal sulfide nanoparticle and their biomedical applications.

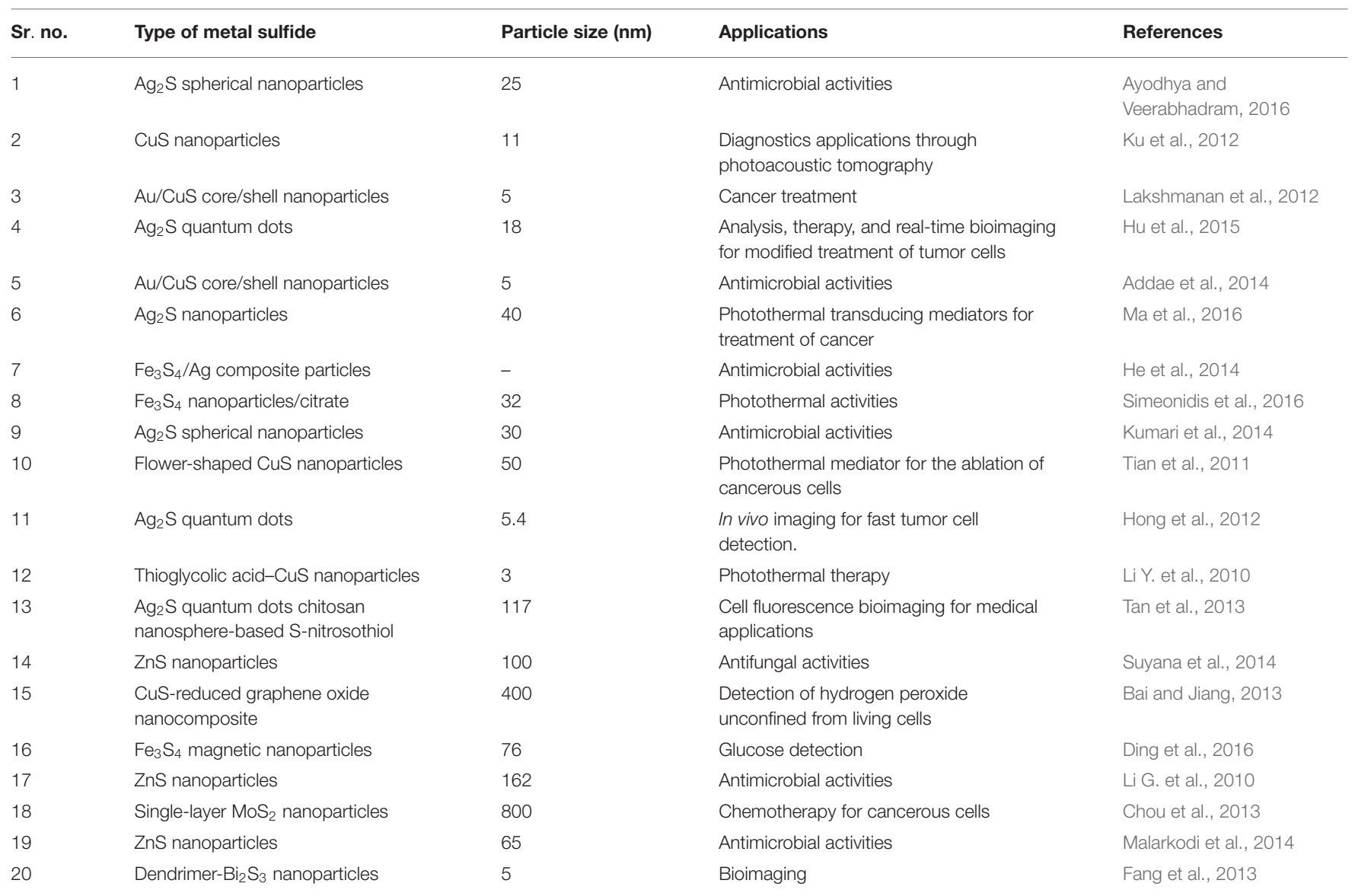

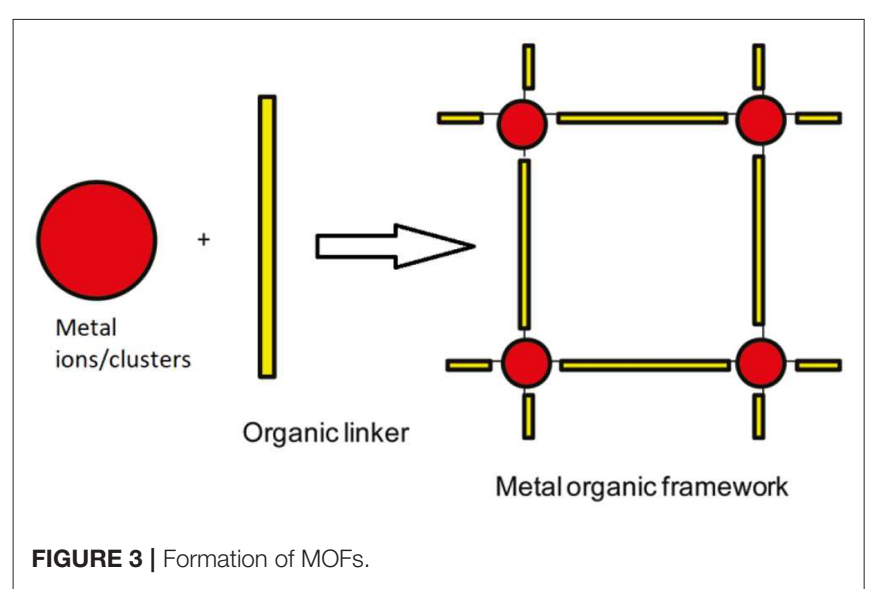

previously. Similarly, Briones et al. (2016) also studied the Zn ion bonded with some other materials, for use in antidiabetic activities. Hidalgo et al. (2017) studied the Mg metallic ion to achieve the $\operatorname{Mg}\left(\mathrm{H}_{4}\right.$ gal $)$ MOF material, which was effectively used against pathogens and used as antioxidant carrier too. The Ag metal ions also got significant attention due to their remarkable properties especially as antimicrobial agent. ArenasVivo et al. (2019) studied the Ag-based MOF material and used against bacterial diseases and achieved significant results. There are some combinations of metals and related linker as shown in Table 5, which worked perfectly for several types of biomedical applications.

\section{SURFACE MODIFICATION STRATEGIES TO IMPROVE PROPERTIES OF METAL-BASED NANOPARTICLES}

The surface properties of new synthesized materials are usually insufficient in terms of biocompatibility, toxicity, adhesion properties, and wettability. Therefore, they should be improved up to sufficient extent prior to any kind of practical application or any potential processing technique such as coating with targeted materials. However, research on metal-based nanoparticles is growing rapidly, and several applications are predicted. Although many kinds of nanomaterials have outstanding physiochemical bulk features, they do not have appropriate surface specificity for special applications. Therefore, it may be essential to upgrade the surface properties. The surface modification of metal-based nanoparticles carried out with some significant advantages. First, the modification provides opportunity to stabilize nanoparticles against agglomeration. Second, it helps 


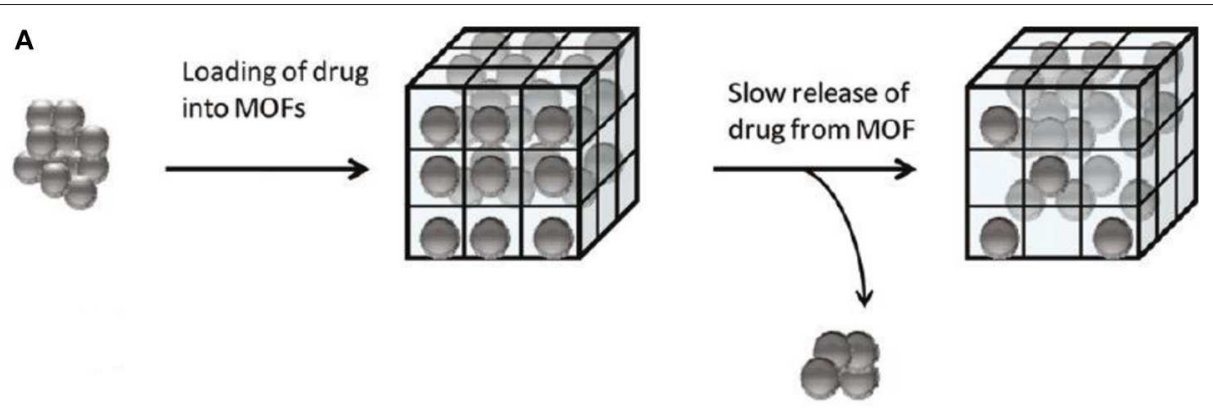

B

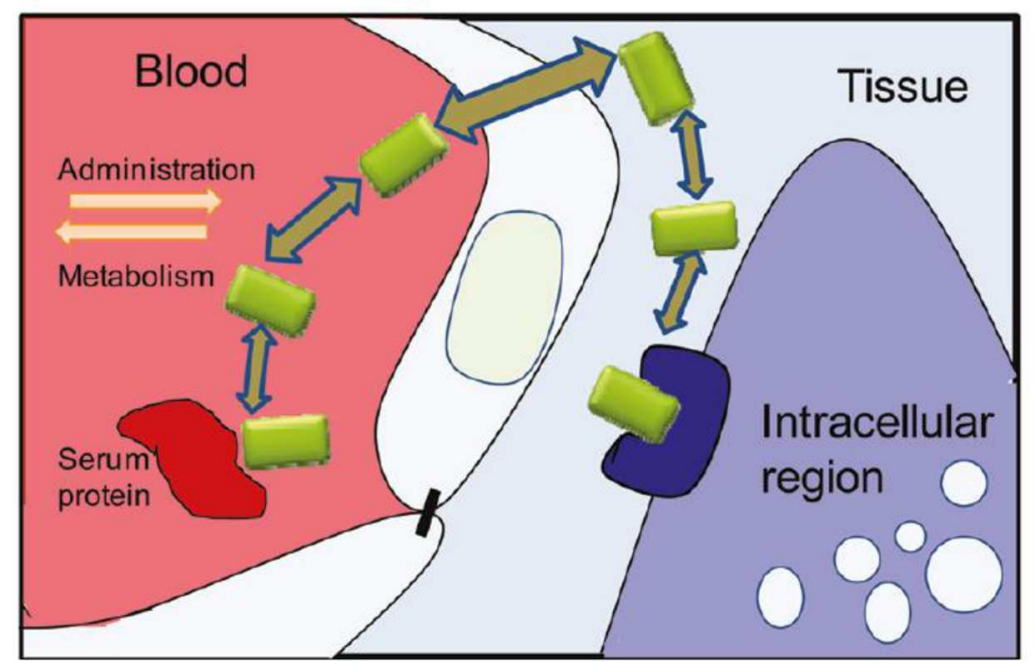

FIGURE 4 | (A) Metal organic frameworks comprehensive scheme as drug delivery vehicles. (B) In vivo conditions elaborated in the deliberate discharge of drugs. Adapted with permission from Keskin and Kizilel (2011).

to empower their self-organization, and third, it creates interest to offer compatibility with others (Viswanathan et al., 2019). For example, when metal nanoparticles are attached with any suitable functional group, it can be made water-soluble. One more example is modification of inorganic (nano-)fillers with organic compounds. The surface modification can evade compatibility and homogeneity difficulties between the nano fillers and organic compounds and thus expand mechanical properties of organic/inorganic composite (Rahman et al., 2002). The surface modification of material that was used as medical kits is also needed to be modified before the treatment process. The clinical advantages achieved after surface modification are mentioned as good antimicrobial effect, high bioactivity, good cell growth and tissue, and increased fatigue power (Izman et al., 2012). The suitable metallic nanoparticles surface modification approaches help to make the material excellent in terms of its properties such as high formability, relatively low modulus, and good mechanical strength. Different types of surface modification approaches are summarized in Figure 5, which was generally used to enhance the biomedical applications by using metal derivatives nanoparticles.

Furthermore, the chemical, mechanical, oxidation, sol-gel, physical vapor deposition, and ion implantation are most popular methods used for surface modification (Kumar et al., 2020). The organic ligand is also considered as one of the good methods of surface modification to achieve the better outcomes. The organic groups are adequate to keep nanoparticles against accumulation; functional groups on nanoparticles surface may permit careful interaction of molecules with metal nanoparticles. The detailed working mechanisms of all these methods are explained previously in literature by many research groups such as Kango et al. (2013), Asri et al. (2017), Qi et al. (2019), Mozetič (2019), Oun et al. (2020), and Liu et al. (2020), respectively.

\section{APPLICATIONS}

There are different types of nanoparticles offering a potential platform for various biological-related applications. Nanoparticles have attracted significant research interest in biomedical applications. The incorporation of nanotechnology into biomedicine has opened new research possibilities. It has allowed valuable insights into molecular biology (Aziz et al., 2019). The nano-sized material has enabled many developments in biomedicine and other biological applications such as drug delivery, anticancer activity (Wani et al., 2016), gene delivery, fluorescent biological labels, protein detection, MRI contrast enhancement, probing of DNA, tissue engineering, 
TABLE 5 | Combinations of metals/related linker and their role in various biomedical applications.

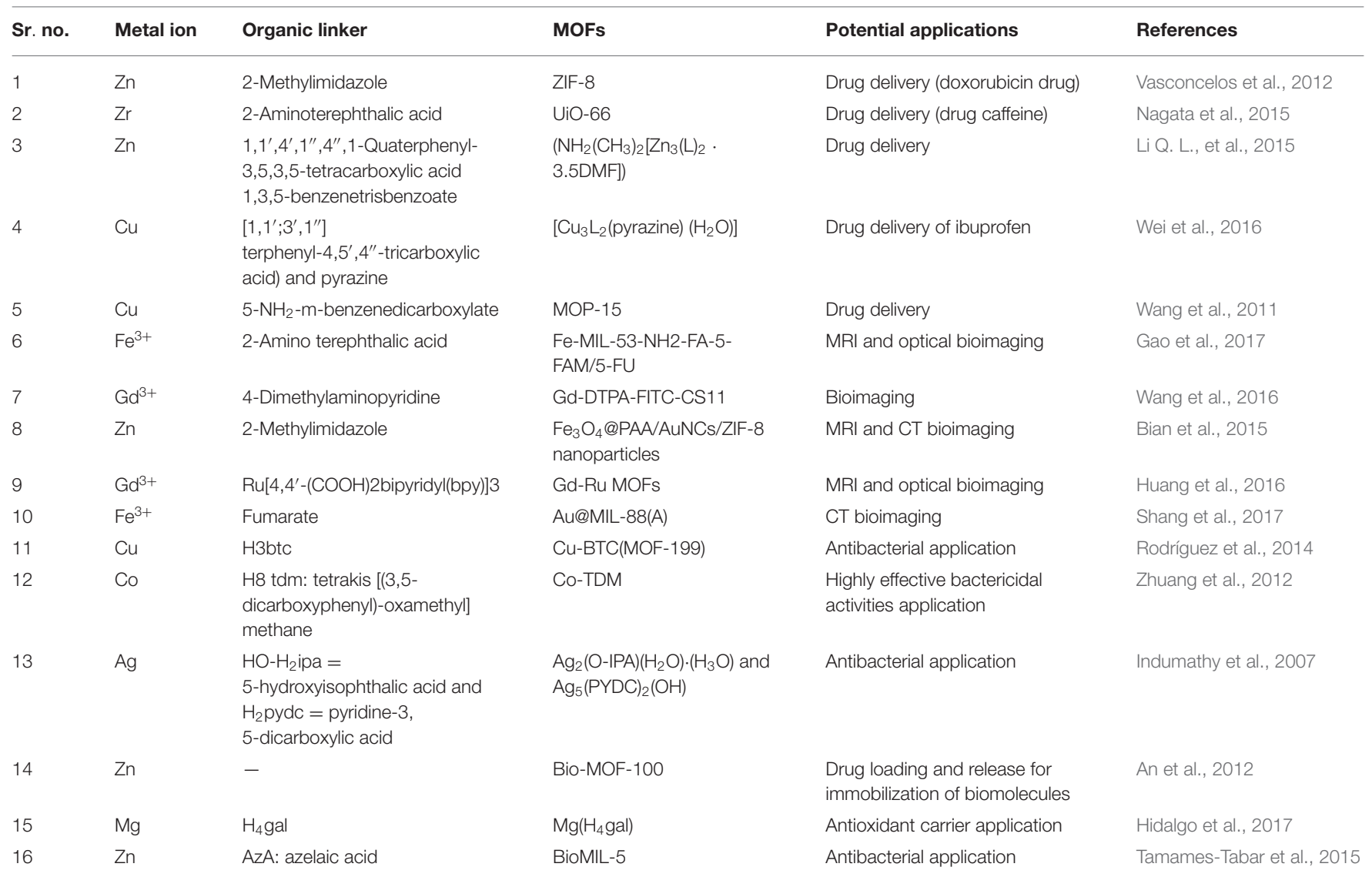

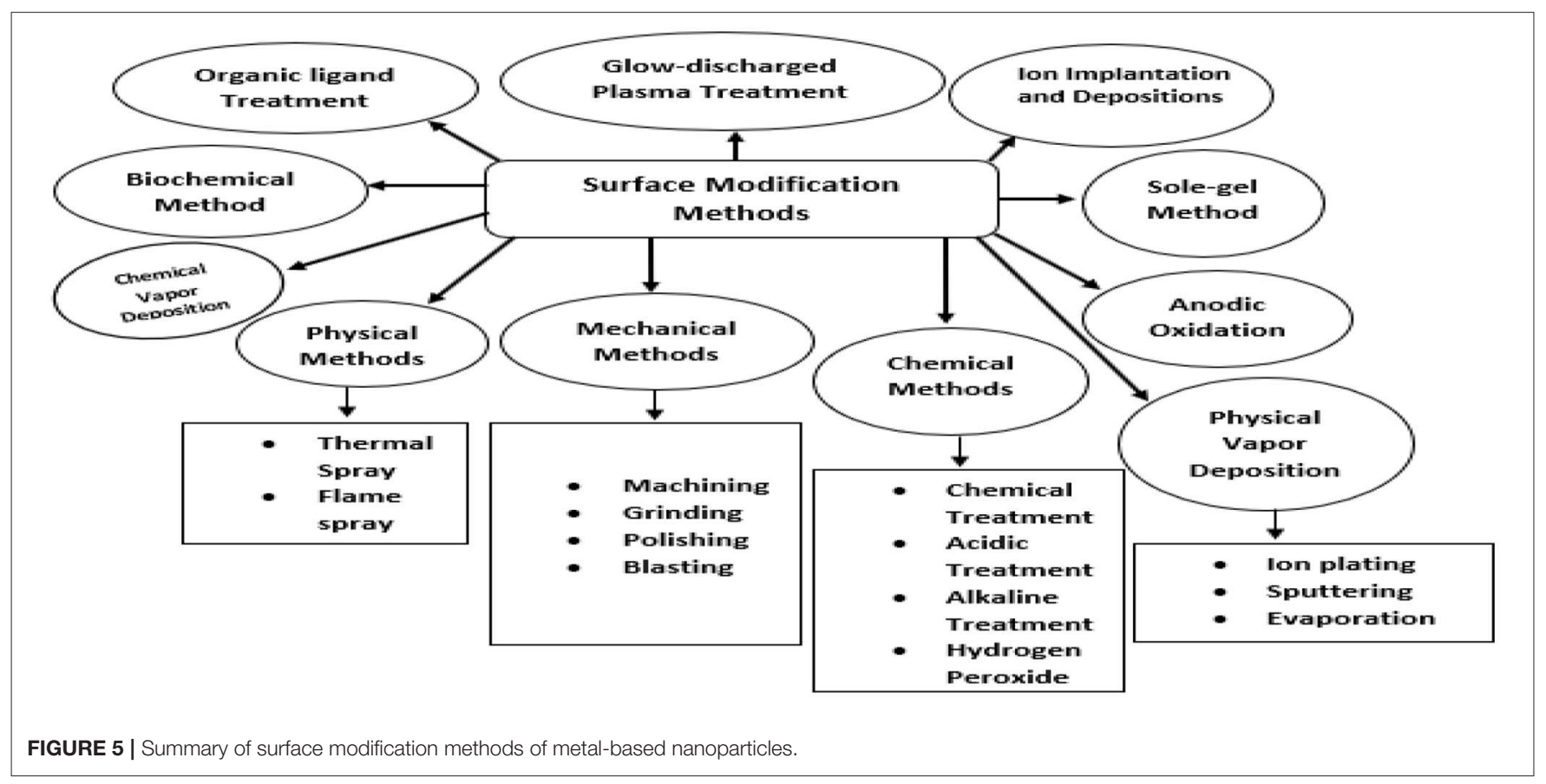


phagokinetic studies, hyperthermia, and filtration of biological based molecular cells.

The nanoparticles nano size makes it appropriate to be used for biolabeling. The nano-sized nanoparticles can react with biomolecules at the surface level, as well as inside the cells, producing valuable signals and specific target for diagnosis and therapeutics process. Therefore, a large variety of nanoparticles with many possibilities of modification with other bio-based material have been explored for further biomedical testing. These new nanoparticles can have potential use in thermal ablation, imaging assays, drug delivery, radiotherapy enhancement, and gene delivery (Bushra et al., 2014). Some of the most important applications of different metallic nanoparticles are summarized as follows.

\section{Antimicrobial Agent}

There are many reported antimicrobial agents that are found toxic to all living organisms. Therefore, to overcome this problem, different inorganic and metal-based antibacterial agents should have good thermal resistance, sustainability, and enhanced stability and synthesized under strict processing conditions (Rajawat and Qureshi, 2012; Hossain et al., 2015; Vijayakumari et al., 2019). Currently, Pt, $\mathrm{Ag}, \mathrm{Au}, \mathrm{TiO}_{2}, \mathrm{ZnO}$, and so on, are the major metallic-based nanoparticles utilized as antibacterial agents. Metallic nanoparticles are mainly used as antimicrobial agents in biomedical applications because of their long-term stability and excellent biocompatibility.

Reported studies have proved that metal-based nanoparticles show biocidal activity against gram-negative and gram-positive bacteria (Franci et al., 2015; Chiriac et al., 2016; Rajeshkumar et al., 2016; Wang L. et al., 2017; Ovais et al., 2019). The antimicrobial effects of metal nanoparticles have been attributed to their nano size and high surface-to-volume ratio, which permits them to penetrate the bacterial membranes. The mechanisms of antibacterial effect of metallic nanoparticles are metal ion release, oxidative stress, and nonoxidative-based stress existing instantaneously as shown in Figure 6. Briefly, these nanoparticles serve only when nanoparticles interact with microbe's cell walls; several approaches for the contact of microbes nanoparticles were used such as van der Waals forces, electrostatic attraction, receptor/ligand, and hydrophobic interactions. After successful contact, metallic nanoparticles can pass through inner membranes, interact with metabolic paths, and induce variations in membrane morphology. Once nanoparticles interact with microbes inside cellular machinery, it acts as to prevent enzyme functions, disable proteins, electrolyte imbalance, induce oxidative stress, and change gene expression scale (Vijayakumari et al., 2019). However, excessive quantity of microbes produces barrier that resists antimicrobial mediators and microbes avoiding the resistant system by forming superantigens. The extracellular polymeric secretion also produces everlasting attachment of microbes.

Three most commonly known antimicrobial mechanisms of metallic nanoparticles are oxidative stress, nonoxidative, and dissolved metal ions. Reactive oxygen species (ROS)-induced oxidative stress is a very active approach of metallic nanoparticles action against microbes. The hydroxyl radical $(\mathrm{OH})$, superoxide radical $\left(\mathrm{O}^{-}\right)$, hydrogen peroxide, and single oxygen are related to ROS and considered as instant stress reactions. These can be condensed through endogenous antioxidants such as catalases and superoxide. In regular circumstances, equilibrium is sustained between clearance and generation of ROS in microbial cells. However, if excessive ROS production is carried out, the intracellular redox state is changed and supports oxidation process. Oxidative stress is a main contributor in fluctuating the microbial membrane penetrability and therefore can mutilation the cell membranes, respectively. Nano metallic ions stimulate oxygen and form ROS ions, as well as hydroxyl radicals, which can delay microbial production (Sangaonkar and Pawar, 2018). Furthermore, another commonly used mechanism is that in which metallic ions are slowly discharged from metal oxides in presence of aqueous medium and later absorbed by cell membranes, which leads to straight connections with functional sets of nucleic acids and proteins. The metallic nanoparticles interactions have extensive effects, which comprise cell physical variations and aberrant enzyme actions, and ultimately disturb usual physiological developments. The Ag and Pd nanoparticles were observed to have antimicrobial effects, which were ascribed to discharge the metallic ions into solution (Shaikh et al., 2019). (Zhao and Ashraf, 2015) studied the Ag nanoparticles mechanism as antimicrobial agent, in which $\mathrm{Ag}$ nanoparticles can go into biofilms and stop the biofilm growth through defeating gene expression. The tremendously nano dimensions particles are more valuable for achieving antimicrobial activities and fighting intracellular microbes. However, Slavin et al. (2017) found that the nano size of $\mathrm{Ag}$ $(5-13 \mathrm{~nm}), \mathrm{Au}(8-9 \mathrm{~nm}), \mathrm{ZnO}(1-12 \mathrm{~nm})$, and $\mathrm{TiO}_{2}(12-17 \mathrm{~nm})$ nanoparticles carried out the excellent antimicrobial actions. The metallic nanoparticles produced from microbes have been used for antimicrobial purpose against pathogenic organisms. For example, biogenic-based Ag nanoparticles synthesized from Bhargavaea indica, Brevibacterium frigoritolerans, and Sporosarcina koreensis exhibited antimicrobial properties against Salmonella enterica, Vibrio parahaemolyticus, B. cereus, Bacillus anthracis, and E. coli (Singh et al., 2016).

Similarly, in case of $\mathrm{Cu}$ nanoparticles synthesized from Sida acuta showed good antimicrobial properties against $S$. aureus, E. coli, and P. vulgaris. The $\mathrm{ZnO}$ also exhibited antibacterial activities against E. coli, S. aureus, and P. aeruginosa (Sangaonkar and Pawar, 2018; Singh A. et al., 2018; Singh P. et al., 2018). Therefore, most metal-based nanoparticles show antimicrobial properties through many mechanisms. This limits the prospect of resistance against microorganisms. To make resistance toward metal-based nanoparticles, bacterial cells would have to undergo multiple instantaneous gene mutations, which are not feasible. Moreover, synthesizing environmentally benign metallic nanoparticles through green method is well documented to enhance the antimicrobial activities toward different pathogenic germs.

\section{Bioimaging Application}

Because $\mathrm{x}$-ray technology was used in medical imaging, several noninvasive methods have been developed and effectively functionalized in different areas of medical research such as drug 


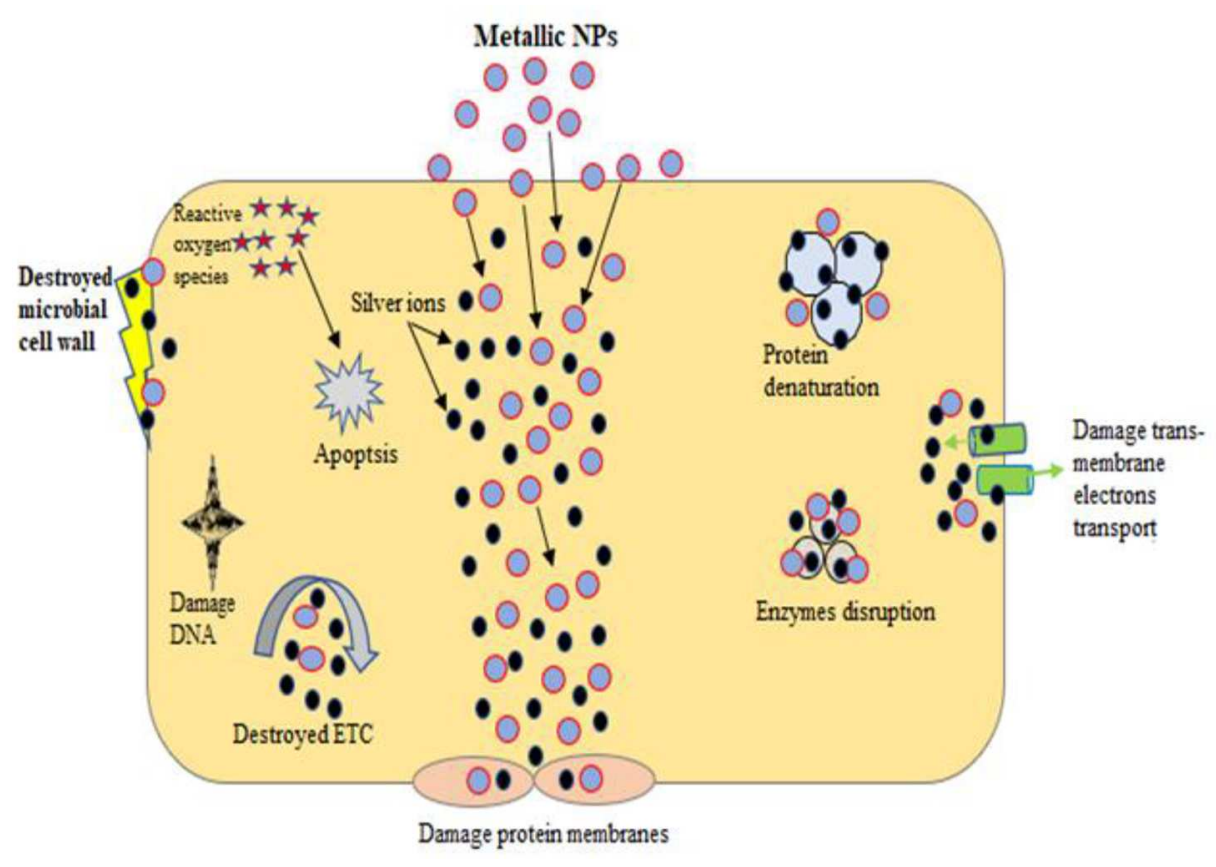

FIGURE 6 | General mechanism of antimicrobial activities of metal-based nanoparticles.

discovery, drug delivery, clinical analysis, and investigation of cellular biology. Clinical imaging studies are carried out in many research areas and significantly contribute in the development of medicine. There are many modified methods of molecular bioimaging systems such as MRI, optical imaging, ultrasound imaging, positron emission tomography, and many others. These have been adapted for in vitro and in vivo biological treatment (Chen et al., 2018; Ferenz and Zhang, 2018; Pratiwi et al., 2019; Wang M. et al., 2019). In the study of metallic nanoparticles, an upgraded bioimaging technology such as MRI and optical imaging has been introduced.

Conde et al. (2012) stated that the noble metals such as gold, silver, and platinum nanoparticles can play valuable roles in instantaneous actuation and tracking due to the absorption of light from biological tissue at near-infrared wavelengths. Common noble metallic nanoparticles have been used in in vivo imaging therapies because of their powerful absorption of near-infrared radiation. Therefore, these nanoparticles can be considered as very active contrasting agents.

However, noble metallic nanomaterials can combine different multiple imaging modalities, which can be utilized to obtain significant information and provide synergistic benefits than any single type of bioimaging technique. The new trend of threedimensional imaging might be achieved by using computed tomography because plane cross-sectional series of images are interweaved through the computer to produce three-dimensional images for clear results. The nanoparticles composites $(\mathrm{FeO} / \mathrm{Si}$ core and Au shell composite) can be used in case of in vivo and composite materials that served as double contrast agents for computed tomography and MRI, which showed good computed tomography attenuation and gave better results of magnetic resonance in hepatoma (Gunko, 2016). Chauhan et al. (2019) proved that Gd-Au nanocomposite can be used for dynamic multimodal imaging as contrast agents.

Zhang W.-H. et al. (2016) studied the dye-loaded fluorescence imaging with $\mathrm{Si}$ nanoparticles in both in vivo and in vitro conditions. Si nanoparticles show excellent biocompatibility, less toxicity, excellent hydrophilicity, and potential optical transparency. Therefore, Si nanoparticles can serve as substrates for production of fluorescent probes, which is an important factor in bioimaging of cells. Li Z. et al. (2015) described the lanthanide-doped up-converting nanoparticles along with the bioimaging application. They suggested that these types of nanomaterials are convertible from low-energy to higherenergy state by using multiphoton processes. The authors elaborated the morphological chemistry of lanthanide-doped up-converting nanoparticles in biomedical applications such as imaging reagents, drug delivery, imaging guidable, and phototherapeutic factor.

Despite these significant progresses in bioimaging, there are still challenges that need to be explored. These low up-conversion productivity of lanthanide-based nanomaterials, problems related to the fabrication of subnano size $(\sim 10 \mathrm{~nm})$ particles, and versatile progress at the commercial level are still unknown. Therefore, these challenges need to be addressed because the future research in bioimaging requires feasibility and reliability.

\section{Drug Delivery}

The encapsulation of drugs by using nanoparticles has been considered a promising and efficient method for drug delivery. Furthermore, the bioviability has been improved through 
incorporating different polymer-based nanoparticles (Nasimi and Haidari, 2013; Lu and Thum, 2019; Vissers et al., 2019). Metallic nanoparticle therapies lowered the therapeutic dosage, which improved the efficiency in treating cancerous cells. Chemotherapeutic agents injected into the patient's body show toxicity and poor compliance. It means that the delivery of therapeutic agent directly to the tumor cells is a critical challenge. Miller-Kleinhenz et al. (2018) studied the Dox-loaded $\mathrm{FeO}$ nanoparticles instantaneously associated with urokinase plasminogen activator receptor for active inhibition of cancerous cell. The targeted FeO-Dox nanoparticles caused powerful tumor development inhibition as compared with nontargeted. So, it is confirmed that the dual targeted FeO-Dox nanoparticles acted on appreciated stage for improved drug delivery approaches. Bogusz et al. (2014) described the hybrid-based nano gels produced from bismuth oxide-based quantum dots with polyvinyl alcohol for resolutions of heat sensing, bioimaging, and especially in drug delivery. Zhong et al. (2014) studied the MOF as potential drug carrier in the presence of $\mathrm{Zn}$ metal ions. The resultant MOF is $\left[\mathrm{NH}_{2}\left(\mathrm{CH}_{3}\right)_{2}\right]-\left[\mathrm{Zn}_{2}(\mathrm{HL}) \mathrm{L} 0.5\right] \mathrm{n} \mathrm{n}\left(8 \mathrm{DMF} 5 \mathrm{H}_{2} \mathrm{O}\right)$, and it employed to load ibuprofen (IBU). The outcomes indicate that $\mathrm{Zn}$ ion can hold higher loading power of IBU, which is up to $50 \%$, and show a longer discharged time within $96 \mathrm{~h}$ in replicated body fluid. Lee et al. (2011) summarized oleic acid-based $\mathrm{FeO}$ nanoparticles in oleic acid-conjugated chitosan (oleyl-chitosan) to observe the layer of nanoparticles in tumor tissues/cells by permeability and holding value under the in vivo condition for systematic practices by IR and magnetic resonance bioimaging mechanisms. In the in vivo assessments, both methods presented clear signal power and development in tumor cells/tissues through an advanced consequence after inoculation of cyanine-5-attached oleyl-chitosan nanoparticles intravenously. The bioimaging of target cells is achieved by using metal nanoparticles (Banerjee et al., 2016; Saini et al., 2016). The metallic nanoparticles react with biomolecules at both cell surfaces (inside and outside). It offers excellent transportation to therapeutics. The different metal nanoparticles and other nano size materials that have been introduced as drug delivery systems and diagnostics are shown in Figure 7. Nanoparticles also influence gene sequence in case of neoplastic cells, which results in cellular inflammation and protein expression such as cancer necrosis factors and so on. These growths of the cancerous cells depend on external and internal signals such as cytoskeletal function, $\mathrm{pH}$, cellular proteins, and nuclear protein with cellular enzymatic sign, growing influence, free radicals, endoplasmic stress, and oxidative events. Kajani et al. (2016) stated that nanomedicine created innovative prospect in the upcoming progress of anticancer approaches. Traditional cancer treatments such as radiotherapy and chemotherapy are limited because of drug toxicity, drug resistance issue, and less specificity of targeted zone. Ag nanoparticles remove all these issues by reducing all drawbacks of aforementioned techniques and enhance the cancer treatment. Ag nanoparticles provide precise targeted drug delivery, and it has ability to cross living barriers. Green synthesis approaches of Ag nanoparticles also offer the delivery of cancer drug to tumor cells for betterment of cancer therapies.
Nanomedicine in injectable form is indispensable to target cancerous cells (Couvreur, 2013; Sanku et al., 2019; Sharma et al., 2019). On the other hand, these metal nanoparticles can simply conjugate with several mediators such as different types of antibodies, peptides, and RNA/DNA to target the various types of cells. These are eco-compatible to extend their flow in vivo for gene and medication delivery applications. They can convert light into other forms of energy, that is, heat; hence, it allows cancer cells to be targeted by thermal ablation. The antisense RNA is a valuable nucleic acid and targets the direction of RNA along with cancer cells (Young et al., 2016). Additionally, cell permeability and drug solubility impose severe challenge in the utilization of nanoparticles as therapy agents. The challenge can be overcome by improving the delivery system using nanotechnology. Generally, multiple nanoparticles are used in drug delivery methods. These have some common limitations that can be solved by changing the size, shape, layers, variety of applicable coating substance, solvents, surface potential, and different fabricating methods.

\section{Tissue Engineering}

The nanoparticles received much attention recently in tissue engineering. Engineering and biological principles are used with practical substitutes of different types of damaged tissues. The nanoparticles that have low toxicity, tailorable properties, contrasting agent activities, targeted delivery potential, and accurate control over behavior make it suitable to use for developing/regenerating tissues (Corchero and Villaverde, 2009). The nanoparticles have been fabricated by using different materials (composites) to enhance its efficiency and role in tissue repairing. Several metallic nanoparticles were synthesized such as $\mathrm{Ti}, \mathrm{Au}, \mathrm{Ag}$, and many others, which showed significant potential in this field. One of the possible uses of Au nanoparticles is in regenerative medicine, which is used in tissue swapping because of development of tumor cells (Lizundia et al., 2018; Bapat et al., 2019; Fathi-Achachelouei et al., 2019). Bioactive glass ceramicbased nanoparticles (BGC nanoparticles) are also very promising material and frequently used in bone tissue regeneration. Covarrubias et al. (2018) reported that the encapsulation of dense BGC nanoparticles into gelatin from chitosan polymer has encouraged the alkaline phosphate activities as compared to other mesoporous BGC nanoparticles. The result showed that the dense chitosan gelatin hydrogel with bioactive nanoparticles showed the highest rate of bone formation (80\%) than others.

Li et al. (2018) also studied the multifunctional polycitrate-siloxane elastomer-based BGC nanoparticles and used it as an effective material in bone tissue regeneration. The titanium nanoparticles have also been used as bone repairing material. It is broadly used in the field of dentistry and orthopedics. It contains properties such as stronger fracture resistance, improved ductility, and effective weight-to-strength ratio. Unfortunately, they carried lower bioactivities, as it does not sustain cell adhesion and growth. Therefore, apatite coatings are considered preferable as bioactive materials. Hence, many methods were used to make the apatite coating around titanium. 


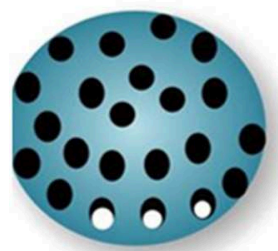

Mesoporous

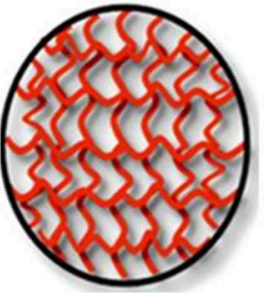

Hydrogel

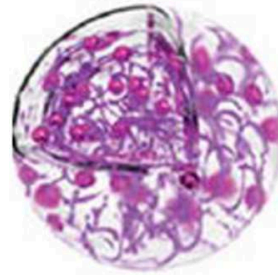

Nanogel
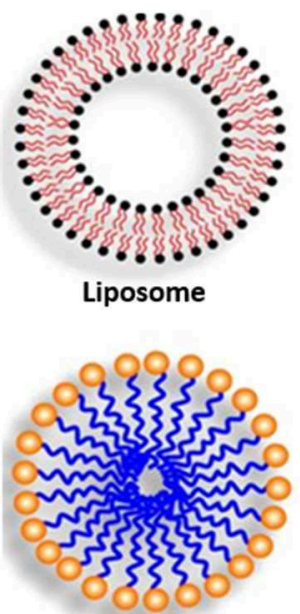

Micelle

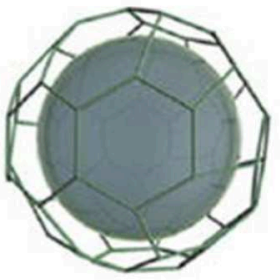

Nanocage

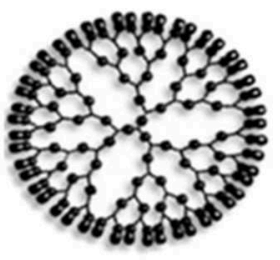

Dendrimer

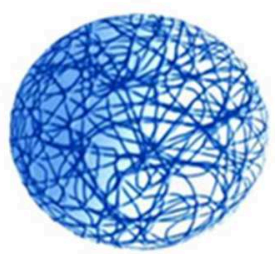

Polymeric Nanoparticles

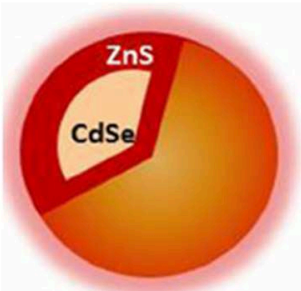

Quantum Dots

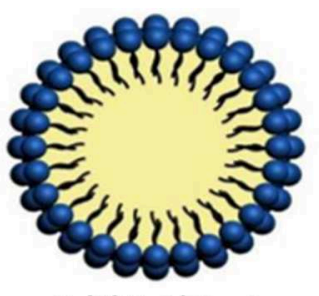

Solid Lipid Carrier

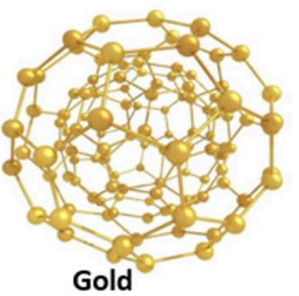

Gold

Nanoparticles

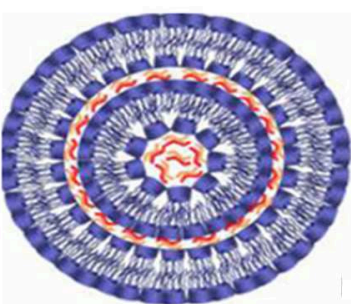

Amphiphilic Cyclodextrins

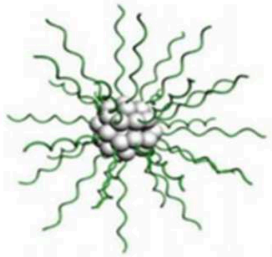

Polymer micelle

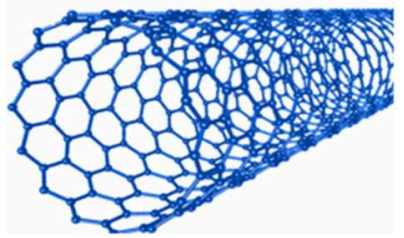

Carbon Nanotubes

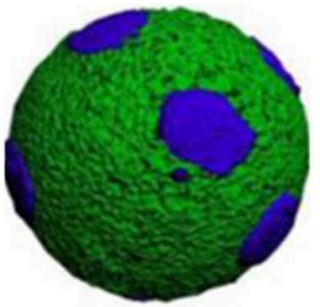

Viral Carrier

FIGURE 7 | Different types of nanocarriers (nanoparticle) serve as drug delivery.

However, this coating also has some limitations such as nonuniformity in thickness, bad adhesion, and lower mechanical stability. Furthermore, stable absorbent structure is mandatory to support different nutrients via cell growth. A real bone is known as a valuable nanocomposite material, prepared by hydroxyapatite crystallites in different organic medium, which mostly consist of collagen. Bone is mechanically tough, so it can be resistant from any mechanical damage. Nanoscale mechanism that leads to such valuable amalgamation is still under consideration (Scott et al., 2013; Walmsley et al., 2015; Azizian et al., 2018; De-Witte et al., 2018). The general mechanism of bone tissue engineering is shown in Figure 8 to summarize the general concept used in bone engineering.

\section{Therapeutic Applications}

The metallic nanoparticles or clusters have several significant and valuable features for therapeutic applications as shown in Figure 9. The study reported that metal nanoparticles have been designated as human immunodeficiency virus (HIV) preventive-therapeutic. In other studies, it has proven that silver nanoparticles can act directly on viral infection by interconnecting with glycoprotein (Liu and Chen, 2016; Saravanan et al., 2018). This type of interconnection prevents the different types of virial binding, which successfully reduces the HIV infection. Therefore, it is well known that metallic

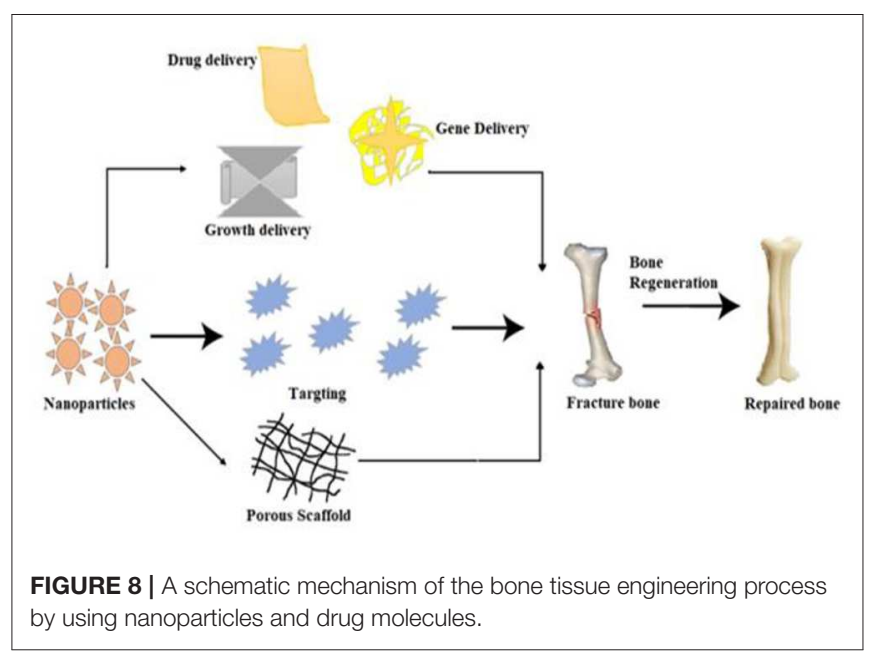

nanoparticles have been used as active antiviral agents to serve against respiratory syncytial, herpesvirus, and influenza.

In case of angiogenesis, the growth of original blood vessels takes place during usual growth and under disease conditions. It plays a vital role in several diseases such as arthritis and cancer. In stable conditions, the angiogenesis is strongly regulated among several proangiogenic evolution factors and a few antiangiogenic 


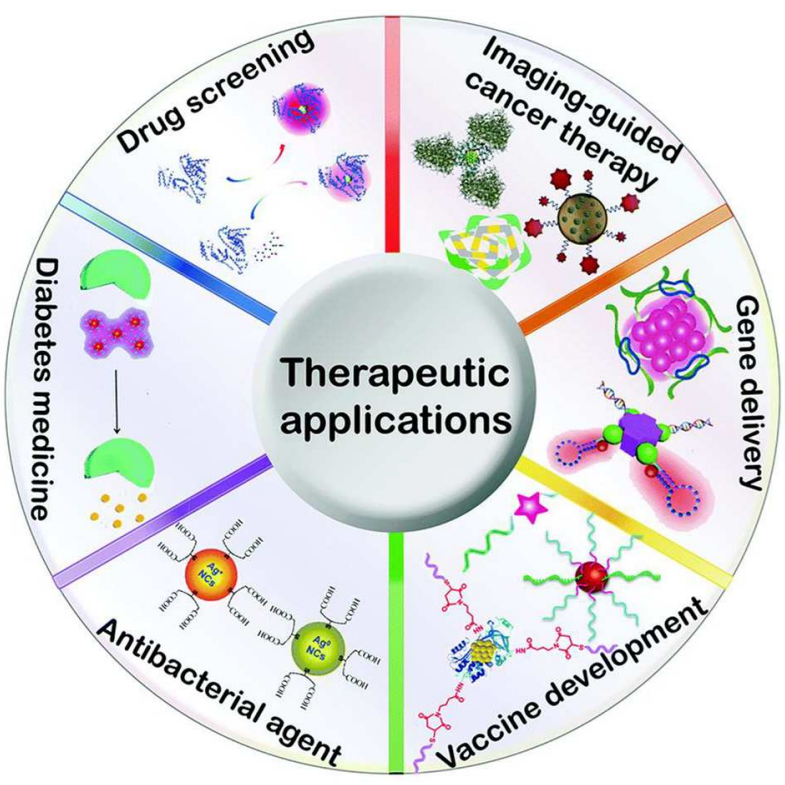

FIGURE 9 | Schematic presentation of metal-based nanoclusters of therapeutic applications. Adapted from Tao et al. (2015), with permission from RSC.

factors such as TSP-1 and platelet factor 4. Ramezani et al. (2008) studied the gold nanoparticles' effect on angiogenesis by using a mouse ear model inoculated with an adenoviral vector of vascular endothelial growth factor (VEGF). Chronic lymphocytic leukemia (CLL) is an irredeemable virus mainly due to apoptosis resistance. This is due to anti-VEGF antibodies, found in CLLbased cells. In CLL therapies, the Au nanoparticles were utilized to enhance performance of contracting agents. They were found to have good biocompatibility, large surface area, and high surface functionalization. The Au nanoparticles and the vascular endothelial growth factor antibodies were found to be involved. Their capacity to execute the CLL cells was measured.

Rheumatoid arthritis is a disease of the joints that arises when body immune system is not working effectively. It attacks the joints that connect bones. A group of researchers from the University of Wollongong, Australia, has assembled a new method for arthritic disease (Soni and Yadav, 2015; Ensafi et al., 2016; Zhang Q. et al., 2016). They introduced an antidrug that can be used through binding with Au nanoparticles, but it has some minor drawbacks. Another research has revealed that $\mathrm{Au}$ nanoparticles can attack macrophages and prevent inflammation. The size of Au nanoparticles is a very important factor in order to reduce the effect of toxicity, for example, a $50 \mathrm{~nm}$ or lesser size particle was more effective in enhancing the immunity of the cells without any side effects (Byeon et al., 2016; Dolati et al., 2016; Nogueira et al., 2016).

\section{FUTURE PERSPECTIVES}

The metal-based nanoparticles seem to have a commanding role in the twenty first century because of their vital role in nanomedicine and other biological applications. The nanoparticles can be fabricated by using several synthetic routes and effectively used in various nanomedical and biological applications. But there is still a need to prepare these nanoparticles on a commercial scale to reduce cost. The natural resources for the preparation of these nanoparticles should be sustainable, inexpensive, eco-friendly, and free from toxic chemical. It is important to produce monodispersed nanoparticles for future research. However, the mechanism to synthesize nanoparticles has not been completely explained at present. Therefore, future research should address the mechanism by which the shape and size of nanoparticles can be controlled. Another major challenge is the need to expand the use of nanoparticles in therapeutic applications and to reduce the level of toxicity. New strategies are being introduced with potential development in nanoscience to overcome the challenges by using noble metal nanoparticles. Prior to extensive use, impact on anthropological health factors needs to be considered.

Nanoscience can play a major role in modified biomedicine. It needs to be explored much more compressively in the future. The noble metal nanoparticles can serve as active agents in diagnosis and other therapeutic applications as they exhibit novel properties at atomic level, as well as at the supramolecular level. At present, there is a high demand for different types of nanomaterials and their composites in the health care, medical, and biological industries. Therefore, an emphasis must be made on the safety precautions to safeguard human health. In-depth studies on safety profiles are required specifically in the case of using metallic nanoparticles in health care. Future research should be directed to investigate the use of specific metal nanoparticles for individual applications.

The preparation of noble metal nanoparticles needs to be up-scaled from laboratory size to commercial medical size in the future. Metallic nanoparticles have been developed and are in an advanced state of testing in multidirectional applications. Currently, it is mainly used for the treatment of cancerous cells. Metal nanoparticles highlight their effectiveness as novel agents for future tumor therapeutic modalities. A question that needs to be answered is: Are the noble metal nanoparticles cytotoxic or biocompatible? Therefore, it is necessary to examine the nanoparticles interactions at laboratory scale and modify the nanoparticles for better biocompatibility with cells (cancerous) to remove injury to normal cells. Modern investigation should focus on the potential applications of nanoparticles at the commercial level, because in general, at present, all research is being conducted at a laboratory scale. Exploration at the commercial level may bring a revolution in the life of human beings.

\section{CONCLUSION}

In this review, the importance of nanoparticles in biological and biomedicine is discussed. Metal-based nanoparticles have received much attention due to extensive medical testing and many other biological applications. Metal-based nanoparticles have potential to control antagonistic effects on different organs, different body tissues, and subcellular, cellular, and protein range because of their unique physicochemical properties. 
Furthermore, as the size of the nanoparticle decreases, some metal nanoparticles ( $\mathrm{Ag}, \mathrm{Au}, \mathrm{Zn}$, and $\mathrm{Cu}$ ) can exhibit high toxicity, while on a comparatively bulk scale it is inactive. Metalmetal oxide or pure metal nanoparticles have been used as an appropriate substitute for antimicrobial studies. Antimicrobial nanoparticles could be used in therapeutics and in the production of medical devices with autodisinfection. It is highly possible that low-cost antimicrobial agents that are simple can be developed with metal, metal oxide, or metal oxide/metal-doped composites. It will serve as an alternative to traditional antibiotics. The noble metal nanoparticles and their composites are of great importance as they have been shown to have antimicrobial properties and used in drug delivery and also play an important role in many medical applications. Furthermore, the metal oxide nanoparticles have limited use due to their toxic effect, usually at high concentrations. It is proposed that ion doping, functionalization process, and conjugated polymer metal oxide nanoparticles

\section{REFERENCES}

Addae, E., Dong, X., McCoy, E., Yang, C., Chen, W., and Yang, L. (2014). Investigation of antimicrobial activity of photothermal therapeutic gold/copper sulfide core/shell nanoparticles to bacterial spores and cells. J. Biol. Eng. 8:11. doi: 10.1186/1754-1611-8-11

Ahamed, M., Alhadlaq, H. A., Khan, M. A., Karuppiah, P., and Al-Dhabi, N. A. (2014). Synthesis, characterization, and antimicrobial activity of copper oxide nanoparticles. J. Nanomater. 2014, 17-21. doi: 10.1155/2014/637858

Aishwarya, S., and Sanjay, K. R. (2020). E. coli-based synthesis of cadmium sulfide nanoparticles, characterization, antimicrobial and cytotoxicity studies. Braz. J. Microbiol. 17, 1-10. doi: 10.1007/s42770-020-00238-9

Allahverdiyev, A. M., Abamor, E. S., Bagirova, M., and Rafailovich, M. (2011). Antimicrobial effects of $\mathrm{TiO}_{2}$ and $\mathrm{Ag}_{2} \mathrm{O}$ nanoparticles against drugresistant bacteria and leishmania parasites. Fut. Microbiol. 6, 933-940. doi: $10.2217 / \mathrm{fmb} .11 .78$

An, J., Farha, O. K., Hupp, J. T., Pohl, E., Yeh, J. I., and Rosi, N. L. (2012). Metal-adeninate vertices for the construction of an exceptionally porous metalorganic framework. Nat. Commun. 3, 1-6. doi: 10.1038/ncomms1618

Arakawa, F. S., Shimabuku-Biadola, Q. L., Fernandes Silva, M., and Bergamasco, R. (2019). Development of a new vacuum impregnation method at room atmosphere to produce silver-copper oxide nanoparticles on activated carbon for antibacterial applications. Environ. Technol. 1, 1-12. doi: 10.1080/09593330.2019.1567607

Arenas-Vivo, A., Amariei, G., Aguado, S., Rosal, R., and Horcajada, P. (2019). An Ag-loaded photoactive nano-metal organic framework as a promising biofilm treatment. Acta Biomater. 97, 490-500. doi: 10.1016/j.actbio.2019.08.011

Argueta-Figueroa, L., Martinez-Alvarez, O., Santos-Cruz, J., GarciaContreras, R., Acosta-Torres, L., de la Fuente-Hernandez, J., et al. (2017). Nanomaterials made of non-toxic metallic sulfides: a systematic review of their potential biomedical applications. Mater. Sci. Eng. C 76, 1305-1315. doi: 10.1016/j.msec.2017.02.120

Asri, R. I., Harun, W. S., Samykano, M., Lah, N. A., Ghani, S. A., Tarlochan, F., et al. (2017). Corrosion and surface modification on biocompatible metals: A review. Mater. Sci. Eng. C. 77, 1261-1274.

Asharani, P., Xinyi, N., Hande, M. P., and Valiyaveettil, S. (2010). DNA damage and p53-mediated growth arrest in human cells treated with platinum nanoparticles. Nanomedicine 5, 51-64. doi: 10.2217/nnm.09.85

Attarde, S. S., and Pandit, S. V. (2020). Anticancer potential of nanogold conjugated toxin GNP-NN-32 from naja naja venom. J. Venom. Anim. Toxins Incl. Trop. Dis. 26, 1-13. doi: 10.1590/1678-9199-jvatitd-2019-0047

Ayodhya, D., and Veerabhadram, G. (2016). Green synthesis, characterization, photocatalytic, fluorescence and antimicrobial activities of Cochlospermum can help to reduce the self-toxicity effect. Finally, it may be considered that metal, metal oxide, or composite nanoparticles with less toxicity will be used in the future for remediation of many dangerous infectious diseases and tumor cells.

\section{AUTHOR CONTRIBUTIONS}

$\mathrm{AY}$ and $\mathrm{KU}$ wrote the first version of manuscript. HA, TP, and AA drawn the figures and tables. MO, II, HQ, and MM provided suggestions and revised the manuscript.

\section{FUNDING}

This research article was financially supported by Universiti Sains Malaysia, 11800 Penang Malaysia under the Research University Grant; 1001/ PKIMIA/8011070). KU gratefully acknowledged the post-doctoral financial support (USM/PPSK/FPD(BW)2/(2019). gossypium capped Ag2S nanoparticles. J. Photochem. Photobiol. B Biol. 157, 57-69. doi: 10.1016/j.jphotobiol.2016.02.002

Azam, A., Ahmed, A. S., Oves, M., Khan, M. S., Habib, S. S., and Memic, A. (2012). Antimicrobial activity of metal oxide nanoparticles against Gram-positive and Gram-negative bacteria: a comparative study. Int. J. Nanomed. 7, 6003-6009. doi: $10.2147 /$ IJN.S35347

Aziz, Z. A. A., Mohd-Nasir, H., Ahmad, A., Setapar, M. S. H., Peng, W. L., Chuo, S. C., et al. (2019). Role of nanotechnology for design and development of cosmeceutical: application in makeup and skin care. Front. Chem. 7:739. doi: 10.3389/fchem.2019.00739

Azizian, S., Hadjizadeh, A., and Niknejad, H. (2018). Chitosan-gelatin porous scaffold incorporated with Chitosan nanoparticles for growth factor delivery in tissue engineering. Carbohydrate Polym. 202, 315-322. doi: 10.1016/j.carbpol.2018.07.023

Bai, J., and Jiang, X. (2013). A facile one-pot synthesis of copper sulfide-decorated reduced graphene oxide composites for enhanced detecting of $\mathrm{H} 2 \mathrm{O} 2$ in biological environments. Anal. Chem. 85, 8095-8101. doi: 10.1021/ac400659u

Banerjee, A., Qi, J., Gogoi, R., Wong, J., and Mitragotri, S. (2016). Role of nanoparticle size, shape and surface chemistry in oral drug delivery. J. Control Release 238, 176-185. doi: 10.1016/j.jconrel.2016.07.051

Banerjee, R. (2018). Nanotechnology in drug delivery: present status and a glimpse into the future. Ther. Deliv. 9, 231-232. doi: 10.4155/tde-2018-0014

Bapat, R. A., Joshi, C. P., Bapat, P., Chaubal, T. V., Pandurangappa, R., Jnanendrappa, N., et al. (2019). The use of nanoparticles as biomaterials in dentistry. Drug Dicov. Today 24, 85-98. doi: 10.1016/j.drudis.2018.08.012

Bera, R., Mandal, S., and Raj, C. R. (2014). Antimicrobial activity of fluorescent ag nanoparticles. Lett. Appl. Microbiol. 58, 520-526. doi: 10.1111/lam.12222

Besinis, A., De Peralta, T., and Handy, R. D. (2014). The antibacterial effects of silver, titanium dioxide and silica dioxide nanoparticles compared to the dental disinfectant chlorhexidine on Streptococcus mutans using a suite of bioassays. Nanotoxicology 8, 1-16. doi: 10.3109/17435390.2012.742935

Bian, R., Wang, T., Zhang, L., Li, L., and Wang, C. (2015). A combination of tri-modal cancer imaging and in vivo drug delivery by metal-organic framework based composite nanoparticles. Biomater Sci. 3, 1270-1278. doi: 10.1039/C5BM00186B

Biswal, N., Martha, S., Subudhi, U., and Parida, K. (2011). Incorporation of silver ions into zirconium titanium phosphate: a novel approach toward antibacterial activity. Ind. Eng. Chem. Res. 50, 9479-9486. doi: 10.1021/ie102199b

Bogusz, K., Tehei, M., Stewart, C., McDonald, M., Cardillo, D., Lerch, M., et al. (2014). Synthesis of potential theranostic system consisting of methotrexate-immobilized (3-aminopropyl) trimethoxysilane coated $\alpha-\mathrm{Bi}_{2} \mathrm{O}_{3}$ nanoparticles for cancer treatment. RSC Adv. 4, 24412-24419. doi: 10.1039/c4ra $02160 f$ 
Briones, D., Fernández, B., Calahorro, A. J., Fairen-Jimenez, D., Sanz, R., Castillejo, F. M., et al. (2016). Highly active anti-diabetic metal-organic framework. Cryst. Growth Des. 16, 537-540. doi: 10.1021/acs.cgd.5b01274

Bushra, R., Shahadat, M., Ahmad, A., Nabi, S., Umar, K., Oves, M., et al. (2014). Synthesis, characterization, antimicrobial activity and applications of polyanilineTi (IV) arsenophosphate adsorbent for the analysis of organic and inorganic pollutants. J. Hazard. Mater. 264, 481-489. doi: 10.1016/j.jhazmat.2013.09.044

Byeon, H. J., Lee, C., Lee, S., Lee, E. S., Choi, H.-G., Park, E.-S., et al. (2016). Pharmaceutical potential of tacrolimus-loaded albumin nanoparticles having targetability to rheumatoid arthritis tissues. Int. J. Pharm. 497, 268-276. doi: 10.1016/j.ijpharm.2015.12.004

Cai, W., Wang, J., Chu, C., Chen, W., Wu, C., and Liu, G. (2019). Metalorganic framework-based stimuli-responsive systems for drug delivery. $A d v$. Sci. 6:1801526. doi: 10.1002/advs.201801526

Chauhan, R., El-Baz, N., Keynton, R. S., James, K. T., Malik, D. A., Zhu, M., et al. (2019). Targeted gold nanoparticle-oligonucleotide contrast agents in combination with a new local voxel-wise MRI analysis algorithm for in vitro imaging of triple-negative breast cancer. Nanomaterials 9, 709-721. doi: 10.3390/nano9050709

Chen, G., Wang, Y., Xie, R., and Gong, S. (2018). A review on core-shell structured unimolecular nanoparticles for biomedical applications. Adv. Drug Deliv. Rev. 130, 58-72. doi: 10.1016/j.addr.2018.07.008

Chen, J., Meng, H., Tian, Y., Yang, R., Du, D., Li, Z., et al. (2019). Recent advances in functionalized $\mathrm{MnO} 2$ nanosheets for biosensing and biomedicine applications. Nanoscale Horiz. 4, 321-338. doi: 10.1039/C8NH00274F

Cheng, Z., Dai, Y., Kang, X., Li, C., Huang, S., Lian, H., et al. (2014). Gelatin-encapsulated iron oxide nanoparticles for platinum (IV) prodrug delivery, enzyme-stimulated release and MRI. Biomater. 35, 6359-6368. doi: 10.1016/j.biomaterials.2014.04.029

Chiriac, V., Stratulat, D., Calin, G., Nichitus, S., Burlui, V., Stadoleanu, C., et al. (2016). Antimicrobial property of zinc based nanoparticles. Mater. Sci. Eng. 133, 012055-012064. doi: 10.1088/1757-899X/133/1/012055

Cho, S. H., Jones, B. L., and Krishnan, S. (2009). The dosimetric feasibility of gold nanoparticle-aided radiation therapy (GNRT) via brachytherapy using low-energy gamma-/x-ray sources. Phys. Med. Biol. 54, 4889-4898. doi: 10.1088/0031-9155/54/16/004

Choi, M.-R., Bardhan, R., Stanton-Maxey, K. J., Badve, S., Nakshatri, H., Stantz, K. M., et al. (2012). Delivery of nanoparticles to brain metastases of breast cancer using a cellular Trojan horse. Cancer Nanotechnol. 3, 47-66. doi: 10.1007/s12645-012-0029-9

Chou, S. S., Kaehr, B., Kim, J., Foley, B. M., De, M., Hopkins, P. E., et al. (2013). Chemically exfoliated MoS2 as near-infrared photothermal agents. Angew. Chem. Int. Ed. 52, 4160-4164. doi: 10.1002/anie.201209229

Conde, J., Doria, G., and Baptista, P. (2012). Noble metal nanoparticles applications in cancer. J. Drug Deliv. 2012, 1-12. doi: 10.1155/2012/751075

Corchero, J. L., and Villaverde, A. (2009). Biomedical applications of distally controlled magnetic nanoparticles. Trends Biotechnol. 27, 468-476. doi: 10.1016/j.tibtech.2009.04.003

Couvreur, P. (2013). Nanoparticles in drug delivery: past, present and future. $A d v$. Drug Deliv. Rev. 65, 21-23. doi: 10.1016/j.addr.2012.04.010

Covarrubias, C., Cádiz, M., Maureira, M., Celhay, I., Cuadra, F., and von Marttens, A. (2018). Bionanocomposite scaffolds based on chitosan-gelatin and nanodimensional bioactive glass particles: in vitro properties and in vivo bone regeneration. J. Biomater. Appl. 32, 1155-1163. doi: 10.1177/0885328218 759042

Crosera, M., Prodi, A., Mauro, M., Pelin, M., Florio, C., Bellomo, F., et al. (2015). Titanium dioxide nanoparticle penetration into the skin and effects on HaCaT cells. Int. J. Environ. Res. Public Health 12, 9282-9297. doi: 10.3390/ijerph120809282

Dahoumane, S. A., Wujcik, E. K., and Jeffryes, C. (2016). Noble metal, oxide and chalcogenide-based nanomaterials from scalable phototrophic culture systems. Enzyme Microb. Technol. 95, 13-27. doi: 10.1016/j.enzmictec.2016.06.008

Dar, A. A., Umar, K., Mir, N. A., Haque, M. M., Muneer, M., and Boxall, C. (2011). Photocatalysed degradation of a herbicide derivative, dinoterb, in aqueous suspension. Res. Chem. Intermediat. 37: 567-578. doi: 10.1007/s11164-011-0299-6
DaRocha, S. R., Heyder, R. S., Bielski, E. R., Guo, A., Steinmaurer, M., and Reineke, J. J. (2019). Inhalation drug products containing nanomaterials. Pharm. Inhal. Aerosol. Technol. 2, 403-412. doi: 10.1201/9780429055201-17

De-Witte, T.-M., Fratila-Apachitei, L. E., Zadpoor, A. A., and Peppas, N. A. (2018). Bone tissue engineering via growth factor delivery: from scaffolds to complex matrices. Regen. Biomater. 5, 197-211. doi: 10.1093/rb/rby013

Dhanasekar, M., Jenefer, V., Nambiar, R. B., Babu, S. G., Selvam, S. P., Neppolian, B., et al. (2018). Ambient light antimicrobial activity of reduced graphene oxide supported metal doped $\mathrm{TiO}_{2}$ nanoparticles and their PVA based polymer nanocomposite films. Mater. Res. Bull. 97, 238-243. doi: 10.1016/j.materresbull.2017.08.056

Ding, C., Yan, Y., Xiang, D., Zhang, C., and Xian, Y. (2016). Magnetic Fe3S4 nanoparticles with peroxidase-like activity, and their use in a photometric enzymatic glucose assay. Microchim. Acta 183, 625-631. doi: 10.1007/s00604-015-1690-6

Dizaj, S. M., Lotfipour, F., Barzegar-Jalali, M., Zarrintan, M. H., and Adibkia, K. (2014). Antimicrobial activity of the metals and metal oxide nanoparticles. Mater. Sci. Eng. C 44, 278-284. doi: 10.1016/j.msec.2014.08.031

Dolati, S., Sadreddini, S., Rostamzadeh, D., Ahmadi, M., Jadidi-Niaragh, F., and Yousefi, M. (2016). Utilization of nanoparticle technology in rheumatoid arthritis treatment. Biomed. Pharm. 80, 30-41. doi: 10.1016/j.biopha.2016.03.004

Dreaden, E. C., Alkilany, A. M., Huang, X., Murphy, C. J., and El-Sayed, M. A. (2012). The golden age: gold nanoparticles for biomedicine. Chem. Soc. Rev. 41, 2740-2779. doi: 10.1039/C1CS15237H

Elahi, N., Kamali, M., and Baghersad, M. H. (2018). Recent biomedical applications of gold nanoparticles: a review. Talanta 184, 537-556. doi: $10.1016 /$ j.talanta.2018.02.088

Ensafi, A. A., Amini, M., Rezaei, B., and Talebi, M. (2016). A novel diagnostic biosensor for distinguishing immunoglobulin mutated and unmutated types of chronic lymphocytic leukemia. Biosens. Bioelectron. 77, 409-415. doi: 10.1016/j.bios.2015.09.063

Esmaeilnejad, A., Mahmoudi, P., Zamanian, A., and Mozafari, M. (2019). Synthesis of titanium oxide nanotubes and their decoration by $\mathrm{MnO}$ nanoparticles for biomedical applications. Ceramics Int. 45, 19275-19282. doi: 10.1016/j.ceramint.2019.06.177

Estelrich, J., Sánchez-Martín, M. J., and Busquets, M. A. (2015). Nanoparticles in magnetic resonance imaging: from simple to dual contrast agents. Int. J. Nanomed. 10, 1727-1741. doi: 10.2147/IJN.S76501

Ewald, A., Hösel, D., Patel, S., Grover, L. M., Barralet, J. E., and Gbureck, U. (2011). Silver-doped calcium phosphate cements with antimicrobial activity. Acta Biomater. 7, 4064-4070. doi: 10.1016/j.actbio.2011.06.049

Fan, G., Dundas, C. M., Zhang, C., Lynd, N. A., and Keitz, B. K. (2018). Sequencedependent peptide surface functionalization of metal-organic frameworks. ACS Appl. Mater Interfaces 10, 18601-18609. doi: 10.1021/acsami.8b05148

Fang, Y., Peng, C., Guo, R., Zheng, L., Qin, J., Zhou, B., et al. (2013). Dendrimerstabilized bismuth sulfide nanoparticles: synthesis, characterization, and potential computed tomography imaging applications. Analyst 138, 3172-3180. doi: $10.1039 / \mathrm{c} 3 \mathrm{an} 00237 \mathrm{c}$

Faraday, M. X. (1857). The Bakerian Lecture. -Experimental relations of gold (and other metals) to light. Philos. Trans. R. Soc. Lond. 31, 145-181.

Fathi-Achachelouei, M., Knopf-Marques, H., Riberio de Silva, C. E., Barthès, J. G. D., Bat, E., Tezcaner, A., et al. (2019). Use of nanoparticles in tissue engineering and regenerative medicine. Front. Bioeng. Biotechnol. 7, 113-119. doi: 10.3389/fbioe.2019.00113

Fellahi, O., Sarma, R. K., Das, M. R., Saikia, R., Marcon, L., Coffinier, Y., et al. (2013). The antimicrobial effect of silicon nanowires decorated with silver and copper nanoparticles. Nanotechnology 24, 495101-495112. doi: 10.1088/0957-4484/24/49/495101

Ferenz, K., and Zhang, C. (2018). Nano-bio-imaging and therapeutic nanoparticles. J. Nanosci. Nanomed. 2, 19-20.

Ferreira, C. A., Ni, D., Rosenkrans, Z. T., and Cai, W. (2019). Radionuclideactivated nanomaterials and their biomedical applications. Angew. Chem. Int. Ed. Engl. 58, 13232-13252. doi: 10.1002/anie.201900594

Franci, G., Falanga, A., Galdiero, S., Palomba, L., Rai, M., Morelli, G., et al. (2015). Silver nanoparticles as potential antibacterial agents. Molecules 20, 8856-8874. doi: $10.3390 /$ molecules 20058856 
Gao, Q., Xie, W., Wang, Y., Wang, D., Guo, Z., Gao, F., et al. (2018). A theranostic nanocomposite system based on radial mesoporous silica hybridized with $\mathrm{Fe} 3 \mathrm{O} 4$ nanoparticles for targeted magnetic field responsive chemotherapy of breast cancer. RSC Adv. 8, 4321-4328. doi: 10.1039/C7RA1 $2446 \mathrm{E}$

Gao, X., Zhai, M., Guan, W., Liu, J., Liu, Z., and Damirin, A. (2017). Controllable synthesis of a smart multifunctional nanoscale metal-organic framework for magnetic resonance/optical imaging and targeted drug delivery. ACS Appl. Mater. Interfaces 9, 3455-3462. doi: 10.1021/acsami.6b14795

Gehrke, H., Pelka, J., Hartinger, C. G., Blank, H., Bleimund, F., Schneider, R., et al. (2011). Platinum nanoparticles and their cellular uptake and DNA platination at non-cytotoxic concentrations. Arch. Toxicol. 85, 799-812. doi: 10.1007/s00204-010-0636-3

George, S., Pokhrel, S., Xia, T., Gilbert, B., Ji, Z., Schowalter, M., et al. (2009). Use of a rapid cytotoxicity screening approach to engineer a safer zinc oxide nanoparticle through iron doping. ACS Nano. 4, 15-29. doi: $10.1021 / \mathrm{nn} 901503 \mathrm{q}$

Giasuddin, A., Jhuma, K., and Haq, A. M. (2012). Use of gold nanoparticles in diagnostics, surgery and medicine: a review. Bangladesh J. Med. Biochem. 5, 56-60. doi: 10.3329/bjmb.v5i2.13346

Goel, S., Chen, F., and Cai, W. (2014). Synthesis and biomedical applications of copper sulfide nanoparticles: from sensors to theranostics. Small 10, 631-645. doi: $10.1002 /$ smll.201301174

Gunko, Y. (2016). Nanoparticles in bioimaging. Nanomaterials 6, 105-108. doi: 10.3390/nano6060105

Guo, B.-L., Han, P., Guo, L.-C., Cao, Y.-Q., Li, A.-D., Kong, J.-Z., et al. (2015). The antibacterial activity of Ta-doped $\mathrm{ZnO}$ nanoparticles. Nanoscale Res. Lett. 10:1047. doi: 10.1186/s11671-015-1047-4

Gurav, D. D., Jia, Y. A., Ye, J., and Qian, K. (2019). Design of plasmonic nanomaterials for diagnostic spectrometry. Nanoscale Adv. 1, 459-469. doi: 10.1039/C8NA00319J

Hadi, S. E.-S., Hamid, H., Vahid, R., Seyed Mohammad Javad, M., and Mohammad, M. (2018). Promising antibacterial effect of copper oxide nanoparticles against several multidrug resistant uropathogens. Pharm. Sci. 24, 213-218. doi: 10.15171/PS.2018.31

Haghighi, F., Roudbar Mohammadi, S., Mohammadi, P., Hosseinkhani, S., and Shipour, R. (2013). Antifungal activity of $\mathrm{TiO}_{2}$ nanoparticles and EDTA on Candida albicans biofilms. Epidemiol. Infect. Microbiol. 1, 33-38.

Hasan, S. (2015). A review on nanoparticles: their synthesis and types. Res. J. Recent Sci. 4, 1-3.

He, Q., Huang, C., and Liu, J. (2014). Preparation, characterization and antibacterial activity of magnetic greigite and Fe3S4/Ag nanoparticles. Nanosci. Nanotechnol. Lett. 6, 10-17. doi: 10.1166/nnl.2014.1727

Hidalgo, T., Cooper, L., Gorman, M., Lozano-Fernández, T., Simón-Vázquez, R., Mouchaham, G., et al. (2017). Crystal structure dependent in vitro antioxidant activity of biocompatible calcium gallate MOFs. J. Mater. Chem. B 5, 2813-2822. doi: 10.1039/C6TB03101C

Hong, G., Robinson, J. T., Zhang, Y., Diao, S., Antaris, A. L., Wang, Q., et al. (2012). In vivo fluorescence imaging with $\mathrm{Ag} 2 \mathrm{~S}$ quantum dots in the second nearinfrared region. Angew. Chem. 51, 9818-9821. doi: 10.1002/anie.201206059

Hossain, K. M. Z., Patel, U., and Ahmed, I. (2015). Development of microspheres for biomedical applications: a review. Progr. Biomater. 4, 1-19. doi: 10.1007/s40204-014-0033-8

Hu, F., Li, C., Zhang, Y., Wang, M., Wu, D., and Wang, Q. (2015). Realtime in vivo visualization of tumor therapy by a near-infrared-II Ag2S quantum dot-based theranostic nanoplatform. Nano Res. 8, 1637-1647. doi: 10.1007/s12274-014-0653-2

Huang, Y., Boamah, P. O., Gong, J., Zhang, Q., Hua, M., and Ye, Y. (2016). Gd (III) complex conjugate of low-molecular-weight chitosan as a contrast agent for magnetic resonance/fluorescence dual-modal imaging. Carbohydr. Polym. 143, 288-295. doi: 10.1016/j.carbpol.2016.02.032

Indumathy, R., Radhika, S., Kanthimathi, M., Weyhermuller, T., and Nair, B. U. (2007). Cobalt complexes of terpyridine ligand: crystal structure and photocleavage of DNA. J. Inorg. Biochem. 101, 434-443. doi: 10.1016/j.jinorgbio.2006.11.002

Izman, S., Abdul-Kadir, M. R., Anwar, M., Nazim, E. M., Rosliza, R., Shah, A., et al. (2012). Surface modification techniques for biomedical grade of titanium alloys: oxidation, carburization and ion implantation processes. Titanium
Alloys-Towards Achieving Enhanced Properties for Diversified Applications. 42, 201-228.

Janson, O., Gururaj, S., Pujari-Palmer, S., Ott, M. K., Strømme, M., Engqvist, H., et al. (2019). Titanium surface modification to enhance antibacterial and bioactive properties while retaining biocompatibility. Mater. Sci. Eng. C 96, 272-279. doi: 10.1016/j.msec.2018.11.021

Joh, D. Y., Sun, L., Stangl, M., Al Zaki, A., Murty, S., Santoiemma, P. P., et al. (2013). Selective targeting of brain tumors with gold nanoparticle-induced radiosensitization. PLoS ONE 8:e62425. doi: 10.1371/journal.pone.0062425

Kajani, A. A., Zarkesh-Esfahani, S. H., Bordbar, A. K., Khosropour, A. R., Razmjou, A., and Kardi, M. (2016). Anticancer effects of silver nanoparticles encapsulated by Taxus baccata extracts. J. Mol. Liq. 223, 549-556. doi: 10.1016/j.molliq.2016.08.064

Kango, S., Kalia, S., Celli, A., Njuguna, J., Habibi, Y., and Kumar, R. (2013). Surface modification of inorganic nanoparticles for development of organicinorganic nanocomposites-A review. Prog. Polym. Sci. 38, 1232-1261. doi: 10.1016/j.progpolymsci.2013.02.003

Keat, C. L., Aziz, A., Eid, A. M., and Elmarzugi, N. A. (2015). Biosynthesis of nanoparticles and silver nanoparticles. Bioresour. Bioproc. 2, 47-58. doi: 10.1186/s40643-015-0076-2

Keskin, S., and Kizilel, S. (2011). Biomedical applications of metal organic frameworks. Ind. Eng. Chem. Res. 50, 1799-1812. doi: 10.1021/ie101312k

Khan, I., Saeed, K., and Khan, I. (2017). Nanoparticles: properties, applications and toxicities. Arabian J. Chem. 12, 908-931. doi: 10.1016/j.arabjc.2017.05.011

Khan, M. A., Ahmad, A., Umar, K., and Nabi, S. A. (2015). Synthesis, characterization, and biological applications of nanocomposites for the removal of heavy metals and dyes. Ind. Eng. Chem. 54, 76-82. doi: 10.1021/ie504148k

Khan, S., Ansari, A. A., Malik, A., Chaudhary, A. A., Syed, J. B., and Khan, A. A. (2019). Preparation, characterizations and in vitro cytotoxic activity of nickel oxide nanoparticles on HT-29 and SW620 colon cancer cell lines. J. Trace Elem. Med. Bio. 52, 12-17. doi: 10.1016/j.jtemb.2018.11.003

Khoshnevisan, K., Maleki, H., Honarvarfard, E., Baharifar, H., Gholami, M., Faridbod, F., et al. (2019). Nanomaterial based electrochemical sensing of the biomarker serotonin: a comprehensive review. Microchim. Acta 186, 49-61. doi: 10.1007/s00604-018-3069-y

Kim, J.-K., Seo, S.-J., Kim, K.-H., Kim, T.-J., Chung, M.-H., Kim, K.-R., et al. (2010). Therapeutic application of metallic nanoparticles combined with particle-induced x-ray emission effect. Nanotechnology 21, 425102-425112. doi: 10.1088/0957-4484/21/42/425102

Kleinauskas, A., Rocha, S., Sahu, S., Sun, Y.-P., and Juzenas, P. (2013). Carboncore silver-shell nanodots as sensitizers for phototherapy and radiotherapy. Nanotechnology 24, 325103-325119. doi: 10.1088/0957-4484/24/32/325103

Ku, G., Zhou, M., Song, S., Huang, Q., Hazle, J., and Li, C. (2012). Copper sulfide nanoparticles as a new class of photoacoustic contrast agent for deep tissue imaging at $1064 \mathrm{~nm}$. ACS Nano. 6, 7489-7496. doi: 10.1021/nn302782y

Kumar, K. A., Sugunamma, V., and Sandeep, N. (2020). Influence of viscous dissipation on MHD flow of micropolar fluid over a slendering stretching surface with modified heat flux model. J. Thermal. Analy. Calorimet. 139, 3661-3674. doi: 10.1007/s10973-019-08694-8

Kumar, H., Venkatesh, N., Bhowmik, H., and Kuila, A. (2018). Metallic nanoparticle: a review. Biomed. J. Sci. Tech. Res. 4, 3765-3775. doi: 10.26717/BJSTR.2018.04.001011

Kumari, P., Chandran, P., and Khan, S. S. (2014). RETRACTED: Synthesis and characterization of silver sulfide nanoparticles for photocatalytic and antimicrobial applications. J. Photochem. Photobiol. B 141, 235-240. doi: 10.1016/j.jphotobiol.2014.09.010

Lakshmanan, S. B., Zou, X., Hossu, M., Ma, L., Yang, C., and Chen, W. (2012). Local field enhanced $\mathrm{Au} / \mathrm{CuS}$ nanocomposites as efficient photothermal transducer agents for cancer treatment. J. Biomed. Nanotechnol. 8, 883-890. doi: $10.1166 /$ jbn.2012.1486

Lee, C. M., Jang, D., Kim, J., Cheong, S. J., Kim, E. M., Jeong, M. H., et al. (2011). Oleyl-chitosan nanoparticles based on a dual probe for optical/MR imaging in vivo. Bioconjug. Chem. 22, 186-192. doi: 10.1021/bc10 $0241 \mathrm{a}$

Leung, Y. H., Ng, A. M., Xu, X., Shen, Z., Gethings, L. A., Wong, M. T., et al. (2014). Mechanisms of antibacterial activity of MgO: non-ROS mediated toxicity of $\mathrm{MgO}$ nanoparticles towards Escherichia coli. Small 10, 1171-1183. doi: $10.1002 / \mathrm{smll} .201302434$ 
Leung, Y. H., Xu, X., Ma, A. P., Liu, F., Ng, A. M., Shen, Z., et al. (2016). Toxicity of $\mathrm{ZnO}$ and $\mathrm{TiO}_{2}$ to Escherichia coli cells. Sci. Rep. 6, 35243-35249. doi: $10.1038 /$ srep35243

Li, G., Zhai, J., Li, D., Fang, X., Jiang, H., Dong, Q., et al. (2010). One-pot synthesis of monodispersed $\mathrm{ZnS}$ nanospheres with high antibacterial activity. J. Mater Chem. 20, 9215-9219. doi: 10.1039/c0jm01776k

Li, Q. L., Wang, J.-P., Liu, W.-C., Zhuang, X.-Y., Liu, J.-Q., Fan, G.-L., et al. (2015). A new $(4,8)$-connected topological MOF as potential drug delivery. Inorg. Chem. Commun. 55, 8-10. doi: 10.1016/j.inoche.2015.02.023

Li, Y., Guo, Y., Niu, W., Chen, M., Xue, Y., Ge, J., et al. (2018). Biodegradable multifunctional bioactive glass-based nanocomposite elastomers with controlled biomineralization activity, real-time bioimaging tracking, and decreased inflammatory response. ACS App. Mater. Interfaces 10, 17722-17731. doi: 10.1021/acsami.8b04856

Li, Y., Lu, W., Huang, Q., Li, C., and Chen, W. (2010). Copper sulfide nanoparticles for photothermal ablation of tumor cells. Nanomedicine5, 1161-1171. doi: $10.2217 / \mathrm{nnm} .10 .85$

Li, Z., and Wong, S. L. (2017). Functionalization of 2D transition metal dichalcogenides for biomedical applications. Mater. Sci. Eng. C 70, 1095-1106. doi: 10.1016/j.msec.2016.03.039

Li, Z., Zhang, Y., La, H., Zhu, R., El-Banna, G., Wei, Y., et al. (2015). Upconverting NIR photons for bioimaging. Nanomaterials 5, 2148-2168. doi: 10.3390/nano5042148

Liu, X., Lee, P. Y., Ho, C. M., Lui, V. C., Chen, Y., Che, C. M., et al. (2010). Silver nanoparticles mediate differential responses in keratinocytes and fibroblasts during skin wound healing. ChemMedChem 5, 468-475. doi: $10.1002 / \mathrm{cmdc} .200900502$

Liu, Y., and Chen, C. (2016). Role of nanotechnology in HIV/AIDS vaccine development. Adv. Drug Deliv. Rev. 103, 76-89. doi: 10.1016/j.addr.2016.02.010

Liu, Y., Wu, S., Saavedra-Mella, F., Nguyen, T. A., Southam, G., Chan, T. S., et al. (2020). Rhizosphere modifications of iron-rich minerals and forms of heavy metals encapsulated in sulfidic tailings hardpan. J. Hazard. Mater. 384:121444. doi: 10.1016/j.jhazmat.2019.121444

Lizundia, E., Goikuria, U., Vilas, J. L., Cristofaro, F., Bruni, G., Fortunati, E., et al. (2018). Metal nanoparticles embedded in cellulose nanocrystal based films: material properties and post-use analysis. Biomacromolecules 19, 2618-2628. doi: 10.1021/acs.biomac.8b00243

Llorens, A., Lloret, E., Picouet, P. A., Trbojevich, R., and Fernandez, A. (2012). Metallic-based micro and nanocomposites in food contact materials and active food packaging. Trends Food Sci. Technol. 24, 19-29. doi: 10.1016/j.tifs.2011.10.001

Locatelli, E., Naddaka, M., Uboldi, C., Loudos, G., Fragogeorgi, E., Molinari, V., et al. (2014). Targeted delivery of silver nanoparticles and alisertib: in vitro and in vivo synergistic effect against glioblastoma. Nanomedicine 9, 839-849. doi: $10.2217 /$ nnm.14.1

Lu, D., and Thum, T. (2019). RNA-based diagnostic and therapeutic strategies for cardiovascular disease. Nat. Rev. Cardiol. 16, 661-674. doi: 10.1038/s41569-019-0218-x

Ma, L., Li, L., Li, X., Deng, L., and Zheng, H. (2016). Silver sulfide nanoparticles as photothermal transducing agents for cancer treatment. J. Nanomater. Mol. Nanotechnol. 5, 10-23. doi: 10.4172/2324-8777.1000182

Madhumitha, G., Elango, G., and Roopan, S. M. (2015). Bio-functionalized doped silver nanoparticles and its antimicrobial studies. J. Sol-Gel Sci. Technol. 73, 476-483. doi: 10.1007/s10971-014-3591-2

Malarkodi, C., Rajeshkumar, S., Paulkumar, K., Vanaja, M., Gnanajobitha, G., and Annadurai, G. (2014). Biosynthesis and antimicrobial activity of semiconductor nanoparticles against oral pathogens. Bioinorg. Chem. Appl. 2014:347167. doi: $10.1155 / 2014 / 347167$

Malka, E., Perelshtein, I., Lipovsky, A., Shalom, Y., Naparstek, L., Perkas, N., et al. (2013). Eradication of multi-drug resistant bacteria by a novel $\mathrm{Zn}$-doped $\mathrm{CuO}$ nanocomposite. Small 9, 4069-4076. doi: 10.1002/smll.201301081

Melancon, M. P., Lu, W., Zhong, M., Zhou, M., Liang, G., Elliott, A. M., et al. (2011). Targeted multifunctional gold-based nanoshells for magnetic resonance-guided laser ablation of head and neck cancer. Biomaterials 32, 7600-7608. doi: 10.1016/j.biomaterials.2011.06.039

Miller-Kleinhenz, J., Guo, X., Qian, W., Zhou, H., Bozeman, E. N., Zhu, L., et al. (2018). Dual-targeting Wnt and uPA receptors using peptide conjugated ultra-small nanoparticle drug carriers inhibited cancer stemcell phenotype in chemo-resistant breast cancer. Biomaterials 152, 47-62. doi: 10.1016/j.biomaterials.2017.10.035

Mir, N. A., Khan, A., Umar, K., and Muneer, M. (2013). Photocatalytic study of a xanthene dye derivative, phloxine $\mathrm{b}$ in aqueous suspension of $\mathrm{TiO}_{2}$ : adsorption isotherm and decolourization kinetics. Environ. Focus 2, 208-216. doi: 10.1166/eef.2013.1052

Mohammadi, G., Nokhodchi, A., Barzegar-Jalali, M., Lotfipour, F., Adibkia, K., Ehyaei, N., et al. (2011). Physicochemical and antibacterial performance characterization of clarithromycin nanoparticles as colloidal drug delivery system. Colloids Surf. B Biointerfaces 88, 39-44. doi: 10.1016/j.colsurfb.2011.05.050

Mohapatra, M., and Anand, S. (2010). Synthesis and applications of nanostructured iron oxides/hydroxides-a review. Int. J. Eng. Sci. Technol. 2, 127-146. doi: 10.4314/ijest.v2i8.63846

Mora, C. L. C., Mueller, A., and Janssen, A. P. G. (2019). Antibacterial Medical Product and Method for Producing Same. Patent no. US 2019/0124915 A1.

Mozetič, M. (2019). Surface modification to improve properties of materials. Materials 12:441.

Nagata, S., Kokado, K., and Sada, K. (2015). Metal-organic framework tethering PNIPAM for ON-OFF controlled release in solution. Chem. Commun. 51, 8614-8617. doi: 10.1039/C5CC02339D

Nasimi, P., and Haidari, M. (2013). Medical use of nanoparticles: drug delivery and diagnosis diseases. Int. J. Green Nanotechnol. 1, 1-5. doi: $10.1177 / 1943089213506978$

Nethi, S. K., Rico-Oller, B., Rodríguez-Diéguez, A., Gómez-Ruiz, S., and Patra, C. R. (2017). Design, synthesis and characterization of doped-titanium oxide nanomaterials with environmental and angiogenic applications. Sci. Total Environ. 599, 1263-1274. doi: 10.1016/j.scitotenv.2017.05.005

Nganga, S., Travan, A., Marsich, E., Donati, I., Söderling, E., Moritz, N., et al. (2013). In vitro antimicrobial properties of silver-polysaccharide coatings on porous fiber-reinforced composites for bone implants. J. Mater. Sci. Mater. Med. 24, 2775-2785. doi: 10.1007/s10856-013-5022-2

Nogueira, E., Gomes, A. C., Preto, A., and Cavaco-Paulo, A. (2016). Folate-targeted nanoparticles for rheumatoid arthritis therapy. Nanomedicine 12, 1113-1126. doi: 10.1016/j.nano.2015.12.365

Olishevska, S., Nickzad, A., and Déziel, E. (2019). Bacillus and Paenibacillus secreted polyketides and peptides involved in controlling human and plant pathogens. Appl. Microbiol. Biotechnol. 103, 1189-1215. doi: 10.1007/s00253-018-9541-0

Osman, I. F., Baumgartner, A., Cemeli, E., Fletcher, J. N., and Anderson, D. (2010). Genotoxicity and cytotoxicity of zinc oxide and titanium dioxide in HEp-2 cells. Nanomedicine 5, 1193-1203. doi: 10.2217/nnm.10.52

Oun, A. A., Shankar, S., and Rhim, J. W. (2020). Multifunctional nanocellulose/metal and metal oxide nanoparticle hybrid nanomaterials. Crit. Rev. Food Sci. Nutrition. 60, 435-460. doi: 10.1080/10408398.2018. 1536966

Ouyang, J., Feng, C., Ji, X., Li, L., Gutti, H. K., Kim, N. Y., et al. (2019). 2D monoelemental germanene quantum dots: synthesis as robust photothermal agents for photonic cancer nanomedicine. Angew Chemi. 131, 13539-13544. doi: 10.1002/anie.201908377

Ovais, M., Zia, N., Khalil, A. T., Ayaz, M., Khalil, A., and Ahmad, I. (2019). Nanoantibiotics: recent developments and future prospects. Front. Clin. Drug Res. Anti Infect. 5, 158-174. doi: 10.2174/9781681086378119050006

Oves, M., Arshad, M., Khan, M. S., Ahmed, A. S., Azam, A., and Ismail, I. M. (2015). Antimicrobial activity of cobalt doped zinc oxide nanoparticles: targeting water borne bacteria. J. Saudi Chem. Soc. 19, 581-588. doi: 10.1016/j.jscs.2015.05.003

Ovsyannikov, V. A., Zamoryanskaya, M. V., Semencha, A. V., Lycheva, K. A., Kol'tsova, T. S., Tolochko, O. V., et al. (2015). Development of bismuth oxidebased nanopreparation for the destruction of malignant neoplasms: theoretical prerequisites, challenges, and practical approaches. Glass Phys. Chem. 41, 533-536. doi: 10.1134/S1087659615050119

Pantic, S., Skodric, S. R., Loncar, Z., and Pantic, I. (2019). Zinc oxide nanoparticles: potential novel applications in cellular physiology, pathology, neurosciences and cancer research. Rev. Adv. Mater. Sci. 58, 17-21. doi: 10.1515/rams-2019-0002 
Pattani, V. P., and Tunnell, J. W. (2012). Nanoparticle-mediated photothermal therapy: a comparative study of heating for different particle types. Lasers Surg. Med. 44, 675-684. doi: 10.1002/lsm.22072

Pelka, J., Gehrke, H., Esselen, M., Türk, M., Crone, M., Bräse, S., et al. (2009). Cellular uptake of platinum nanoparticles in human colon carcinoma cells and their impact on cellular redox systems and DNA integrity. Chem. Res. Toxicol. 22, 649-659. doi: 10.1021/tx800354g

Porcel, E., Liehn, S., Remitta, H., Usami, N., Kobayashi, K., and Furusawa, Y. (2010). Platinum nanoparticles: a promising material for future cancer therapy. Nanothechnology 21, 85103-85112. doi: 10.1088/0957-4484/21/8/085103

Prasanna, S. S., Balaji, K., Pandey, S., and Rana, S. (2019). "Metal oxide based nanomaterials and their polymer nanocomposites," in Nanomaterials and Polymer Nanocomposites, eds N. Karak (Amsterdam: Elsevier Inc.), 123-144.

Pratiwi, F. W., Kuo, C. W., Chen, B.-C., and Chen, P. (2019). Recent advances in the use of fluorescent nanoparticles for bioimaging. Nanomedicine 14, 1759-1769. doi: 10.2217/nnm-2019-0105

Qi, K., Cheng, B., Yu, J., and Ho, W. (2019). Review on the improvement of the photocatalytic and antibacterial activities of $\mathrm{ZnO}$. J. Alloys. Comp. 727, 792-820. doi: 10.1016/j.jallcom.2017.08.142

Rahman, M. M., Karim, M. R., Alam, M. M., Zaman, M. B., Alharthi, N., Alharbi, H., et al. (2002). Facile and efficient 3-chlorophenol sensor development based on photolum.enescent core-shell CdSe/ZnS quantum dots. Sci. Rep. 10, 1-10.

Rai, M., Yadav, A., and Gade, A. (2009). Silver nanoparticles as a new generation of antimicrobials. Biotechnol. Adv. 27, 76-83. doi: 10.1016/j.biotechadv.2008.09.002

Rajawat, S., and Qureshi, M. S. (2012). Comparative study on bactericidal effect of silver nanoparticles, synthesized using green technology, in combination with antibiotics on Salmonella typhi. J. Biomater. Nanobiotechnol. 3, 480-497. doi: 10.4236/jbnb.2012.34049

Rajeshkumar, S., Malarkodi, C., Vanaja, M., and Annadurai, G. (2016). Anticancer and enhanced antimicrobial activity of biosynthesizd silver nanoparticles against clinical pathogens. J. Mol. Struct. 1116, 165-173. doi: 10.1016/j.molstruc.2016.03.044

Ramezani, N., Ehsanfar, Z., Shamsa, F., Amin, G., Shahverdi, H. R., Esfahani, H. R. M., et al. (2008). Screening of medicinal plant methanol extracts for the synthesis of gold nanoparticles by their reducing potential. Zeitschrift für Naturforschung B 63, 903-908. doi: 10.1515/znb-2008-0715

Rathore, B., Sunwoo, K., Jangili, P., Kim, J., Kim, J. H., Huang, M., et al. (2019). Nanomaterial designing strategies related to cell lysosome and their biomedical applications: a review. Biomaterials 211, 25-47. doi: 10.1016/j.biomaterials.2019.05.002

Rekha, K., Nirmala, M., Nair, M. G., and Anukaliani, A. (2010). Structural, optical, photocatalytic and antibacterial activity of zinc oxide and manganese doped zinc oxide nanoparticles. Phys. B Condensed Mat. 405, 3180-3185. doi: 10.1016/j.physb.2010.04.042

Roa, W., Xiong, Y., Chen, J., Yang, X., Song, K., Yang, X., et al. (2012). Pharmacokinetic and toxicological evaluation of multi-functional thiol-6fluoro-6-deoxy-D-glucose gold nanoparticles in vivo. Nanotechnology 23, 375101-375117. doi: 10.1088/0957-4484/23/37/375101

Roa, W., Zhang, X., Guo, L., Shaw, A., Hu, X., Xiong, Y., et al. (2009). Gold nanoparticle sensitize radiotherapy of prostate cancer cells by regulation of the cell cycle. Nanotechnology 20, 375101-375112. doi: 10.1088/0957-4484/20/37/375101

Rodríguez, H. S., Hinestroza, J. P., Ochoa-Puentes, C., Sierra, C. A., and Soto, C. Y. (2014). Antibacterial activity against Escherichia coli of Cu-BTC (MOF-199) metal-organic framework immobilized onto cellulosic fibers. J. Appl. Polym. Sci. 131, 40815-40820. doi: 10.1002/app.40815

Roy, A. S., Parveen, A., Koppalkar, A. R., and Prasad, M. A. (2010). Effect of nano-titanium dioxide with different antibiotics against methicillinresistant Staphylococcus aureus. J. Biomater. Nanobiotechnol. 1, 37-49. doi: 10.4236/jbnb.2010.11005

Sabella, S., Brunetti, V., Vecchio, G., Galeone, A., Maiorano, G., Cingolani, R., et al. (2011). Toxicity of citrate-capped Au nanoparticles: an in vitro and in vivo assessment. J. Nanopart. Res. 13, 6821-6835. doi: 10.1007/s11051-011-0590-x

Saini, P., Ganugula, R., Arora, M., and Kumar, M. R. (2016). The next generation non-competitive active polyester nanosystems for transferrin receptor-mediated peroral transport utilizing gambogic acid as a ligand. Sci. Rep. 6:29501. doi: 10.1038/srep29501
Salas, P., Odzak, N., Echegoyen, Y., Kägi, R., Sancho, M. C., and Navarro, E. (2019). The role of size and protein shells in the toxicity to algal photosynthesis induced by ionic silver delivered from silver nanoparticles. Sci. Total Environ. 692, 233-239. doi: 10.1016/j.scitotenv.2019.07.237

Salem, W., Leitner, D. R., Zingl, F. G., Schratter, G., Prassl, R., Goessler, W., et al. (2015). Antibacterial activity of silver and zinc nanoparticles against Vibrio cholerae and enterotoxic Escherichia coli. Int. J. Med. Microbiol. 305, 85-95. doi: 10.1016/j.ijmm.2014.11.005

Samberg, M. E., Loboa, E. G., Oldenburg, S. J., and Monteiro-Riviere, N. A. (2012). Silver nanoparticles do not influence stem cell differentiation but cause minimal toxicity. Nanomedicine 7, 1197-1209. doi: 10.2217/nnm.12.18

Samberg, M. E., Oldenburg, S. J., and Monteiro-Riviere, N. A. (2009). Evaluation of silver nanoparticle toxicity in skin in vivo and keratinocytes in vitro. Environ. Health Perspect. 118, 407-413. doi: 10.1289/ehp.0901398

Sangaonkar, G. M., and Pawar, K. D. (2018). Garcinia indica mediated biogenic synthesis of silver nanoparticles with antibacterial and antioxidant activities. Coll. Surf. B Biointerfaces 164, 210-217. doi: 10.1016/j.colsurfb.2018.01.044

Sangeetha, S., Ramamoorthy, U., Sreeram, K. J., and Nair, B. U. (2012). Enhancing collagen stability through nanostructures containing chromium (III) oxide. Coll. Surf. B Biointerfaces 100, 36-41. doi: 10.1016/j.colsurfb.2012.05.015

Sankar, R., Maheswari, R., Karthik, S., Shivashangari, K. S., and Ravikumar, V. (2014). Anticancer activity of Ficus religiosa engineered copper oxide nanoparticles. Mater. Sci. Eng. C 44, 234-239. doi: 10.1016/j.msec.2014.08.030

Sanku, R. K., Karakus, O. O., Ilies, M., and Ilies, M. A. (2019). "Inclusion complexes in drug delivery and drug targeting: formation, characterization, and biological applications," in Targeted Nanosystems for Therapeutic Applications: New Concepts, Dynamic Properties, Efficiency, and Toxicity, eds K. Sakurai and M. A. Ilies (Pennsylvania, PA: ACS Publications), 187-221.

Saravanan, M., Asmalash, T., Gebrekidan, A., Gebreegziabiher, D., Araya, T., Hilekiros, H., et al. (2018). Nano-medicine as a newly emerging approach to combat human immunodeficiency virus (HIV). Pharm. Nanotechnol. 6, 17-27. doi: 10.2174/2211738506666180209095710

Sathyanarayanan, M. B., Balachandranath, R., Genji Srinivasulu, Y., Kannaiyan, S. K., and Subbiahdoss, G. (2013). The effect of gold and iron-oxide nanoparticles on biofilm-forming pathogens. ISRN Microbiol. 2013:272086. doi: $10.1155 / 2013 / 272086$

Schrand, A. M., Rahman, M. F., Hussain, S. M., Schlager, J. J., Smith, D. A., and Syed, A. F. (2010). Metal-based nanoparticles and their toxicity assessment. Nanomed. Nanobiotechnol. 2, 544-568. doi: 10.1002/wnan.103

Scott, T. G., Blackburn, G., Ashley, M., Bayer, I. S., Ghosh, A., Biris, A. S., et al. (2013). Advances in bionanomaterials for bone tissue engineering. J. Nanosci. Nanotechnol. 13, 1-22. doi: 10.1166/jnn.2013.6733

Shaikh, S., Nazam, N., Rizvi, S. M. D., Ahmad, K., Baig, M. H., Lee, E. J., et al. (2019). Mechanistic insights into the antimicrobial actions of metallic nanoparticles and their implications for multidrug resistance. Inter. J. Mol. Sci. 20:2468. doi: 10.3390/ijms20102468

Shang, W., Zeng, C., Du, Y., Hui, H., Liang, X., Chi, C., et al. (2017). Coreshell gold Nanorod@ metal-organic framework nanoprobes for multimodality diagnosis of glioma. Adv. Mater. 29:1604381. doi: 10.1002/adma.201604381

Shanmuganathan, R., Karuppusamy, I., Saravanan, M., Muthukumar, H., Ponnuchamy, K., Ramkumar, V. S., et al. (2019). Synthesis of silver nanoparticles and their biomedical applications-a comprehensive review. Curr. Pharm. Des. 25, 2650-2660. doi: 10.2174/1381612825666190708185506

Sharma, G., Sharma, A. R., Lee, S.-S., Bhattacharya, M., Nam, J.-S., and Chakraborty, C. (2019). Advances in nanocarriers enabled brain targeted drug delivery across blood brain barrier. Int. J. Pharm. 559, 360-372. doi: 10.1016/j.ijpharm.2019.01.056

Shi, H., Ye, X., He, X., Wang, K., Cui, W., He, D., et al. (2014). Au@ Ag/Au nanoparticles assembled with activatable aptamer probes as smart "nanodoctors" for image-guided cancer thermotherapy. Nanoscale 6, 8754-8761. doi: 10.1039/C4NR01927J

Shivashankarappa, A., and Sanjay, K. R. (2015). Study on biological synthesis of cadmium sulfide nanoparticles by Bacillus licheniformis and its antimicrobial properties against food borne pathogens. Nanosci. Nanotechnol. Res. 3, 6-15. doi: 10.12691/nnr-3-1-2

Siddiqi, K. S., and Husen, A. (2017). Recent advances in plant-mediated engineered gold nanoparticles and their application in biological system. J. Trace Elem. Med. Biol. 40, 10-23. doi: 10.1016/j.jtemb.2016.11.012 
Silva, D. D. M., and Rocha, T.L. (2019). Ecotoxicity of nanomaterials in amphibians: a critical review. Sci. Total Environ. 686, 332-344. doi: 10.1016/j.scitotenv.2019.05.487

Simeonidis, K., Liébana-Viñas, S., Wiedwald, U., Ma, Z., Li, Z.-A., Spasova, M., et al. (2016). A versatile large-scale and green process for synthesizing magnetic nanoparticles with tunable magnetic hyperthermia features. RSC Adv. 6, 53107-53117. doi: 10.1039/C6RA09362K

Singh, A., Singh, N., Afzal, S., Singh, T., and Hussain, I. (2018). Zinc oxide nanoparticles: a review of their biological synthesis, antimicrobial activity, uptake, translocation and biotransformation in plants. J. Mater. Sci. 53, 185-201. doi: 10.1007/s10853-017-1544-1

Singh, P., Garg, A., Pandit, S., Mokkapati, V., and Mijakovic, I. (2018), Antimicrobial effects of biogenic nanoparticles. Nanomaterials 8, 1009-1019. doi: 10.3390/nano8121009

Singh, P., Singh, H., Kim, Y. J., Mathiyalagan, R., Wang, C., and Yang, D. C. (2016). Extracellular synthesis of silver and gold nanoparticles by Sporosarcina koreensis DC4 and their biological applications. Enzyme. Microb. Technol. 86, 75-83. doi: 10.1016/j.enzmictec.2016.02.005

Sirelkhatim, A., Mahmud, S., Seeni, A., Kaus, N. H. M., Ann, L. C., Bakhori, S. K. M., et al. (2015). Review on zinc oxide nanoparticles: antibacterial activity and toxicity mechanism. NanoMicro Lett. 7, 219-242. doi: 10.1007/s40820-015-0040-x

Slavin, Y. N., Asnis, J., Hafeli, U. O., and Bach, H. (2017). Metal nanoparticles: understanding the mechanisms behind antibacterial activity. J. Nanobiotechnol. 15:65. doi: 10.1186/s12951-017-0308-Z

Soni, G., and Yadav, K. S. (2015). Applications of nanoparticles in treatment and diagnosis of leukemia. Mater. Sci. Eng. C 47, 156-164. doi: $10.1016 /$ j.msec.2014.10.043

Srivastava, N. (2014). Iron nanoparticles induced toxicity in Sesbania cannabina: a morphological aspect. Adv. Sci. Focus 2, 135-139. doi: 10.1166/asfo.2014.1088

Subramaniam, V. D., Ramachndran, M., Marotta, F., Banerjee, A., Sun, X. F., and Pathak, S. (2019). Comparative study on anti-proliferative potentials of zinc oxide and aluminium oxide nanoparticles in colon cancer cells. Acta BioMed. 90, 241-247. doi: 10.23750/abm.v90i2.6939

Sultana, S., Khan,. M. Z., Umar, K., Ahmed, A. S., and Shahadat, M. (2015). $\mathrm{SnO}_{2}$-SrO based nanocomposites and their photocatalytic activity for the treatment of organic pollutants. J. Mol. Struct. 1098, 393-399. doi: 10.1016/j.molstruc.2015.06.032

Sun, L., Joh, D., Stangl, M., Al-Zaki, A., Murty, S., Alonso-Basanta, M., et al. (2013). Selective targeting of brain tumors with nanoparticle-induced radiosensitization and contrast enhancement. Pract. Radiat. Oncol. 3, S19-S20. doi: 10.1016/j.prro.2013.01.067

Suyana, P., Kumar, S. N., Kumar, B. D., Nair, B. N., Pillai, S. C., Mohamed, A. P., et al. (2014). Antifungal properties of nanosized $\mathrm{ZnS}$ particles synthesised by sonochemical precipitation. RSC Adv. 4, 8439-8445. doi: 10.1039/c3ra $46642 \mathrm{f}$

Swaminathan, M., and Sharma, N. K. (2019). Antimicrobial activity of the engineered nanoparticles used as coating agents. Handb. Ecomater. 549-563. doi: 10.1007/978-3-319-68255-6_1

Szostak, K., Ostaszewski, P., Pulit-Prociak, J., and Banach, M. (2019). Bismuth oxide nanoparticles in drug delivery systems. Pharm. Chem. J. 53, 48-51. doi: 10.1007/s11094-019-01954-9

Tamames-Tabar, C., Imbuluzqueta, E., Guillou, N., Serre, C., Miller, S., Elkaïm, E., et al. (2015). A Zn azelate MOF: combining antibacterial effect. Cryst. Eng. Comm. 17, 456-462. doi: 10.1039/C4CE00885E

Tan, L., Wan, A., and Li, H. (2013). Ag2S quantum dots conjugated chitosan nanospheres toward light-triggered nitric oxide release and nearinfrared fluorescence imaging. Langmuir 29, 15032-15042. doi: 10.1021/la4 $03028 \mathrm{j}$

Tao, Y., Li, M., Ren, J., and Qu, X. (2015). Metal nanoclusters: novel probes for diagnostic and therapeutic applications. Chem. Soc. Rev. 44, 8636-8663. doi: $10.1039 / \mathrm{C} 5 \mathrm{CS} 00607 \mathrm{D}$

Tian, Q., Tang, M., Sun, Y., Zou, R., Chen, Z., Zhu, M., et al. (2011). Hydrophilic flower-like CuS superstructures as an efficient $980 \mathrm{~nm}$ laser-driven photothermal agent for ablation of cancer cells. Adv. Mater. 23, 3542-3547. doi: 10.1002/adma.201101295

Tomar, A., and Garg, G. (2013). Short review on application of gold nanoparticles. Glob. J. Pharmacol. 7, 34-38.
Tong, S., Zhu, H., and Bao, G., (2019). Magnetic iron oxide nanoparticles for disease detection and therapy. Mater. Today 31, 86-99. doi: 10.1016/j.mattod.2019.06.003

Topete, A., Alatorre-Meda, M., Iglesias, P., Villar-Alvarez, E. M., Barbosa, S., Costoya, J. A., et al. (2014). Fluorescent drug-loaded, polymeric-based, branched gold nanoshells for localized multimodal therapy and imaging of tumoral cells. ACS Nano 8, 2725-2738. doi: 10.1021/nn406425h

Trinidad, A. J., Hong, S. J., Peng, Q., Madsen, S. J., and Hirschberg, H. (2014). Combined concurrent photodynamic and gold nanoshell loaded macrophagemediated photothermal therapies: an in vitro study on squamous cell head and neck carcinoma. Lasers Surg. Med. 46, 310-318. doi: 10.1002/1sm.22235

Umar, K., Aris, A., Ahmad, H., Parveen, T., Jaafar, J., Majid, Z. A., et al. (2016). Synthesis of visible light active doped $\mathrm{TiO}_{2}$ for the degradation of organic pollutants-methylene blue and glyphosate. J. Anal. Sci. Technol. 7, 29-36. doi: 10.1186/s40543-016-0109-2

Umar, K., Haque, M. M., Mir, N. A., Muneer, M., and Farooqi, I. H. (2013). Titanium dioxide-mediated photocatalysed mineralization of two selected organic pollutants in aqueous suspensions. J. Adv. Oxid. Technol. 16, 252-260. doi: 10.1515/jaots-2013-0205

Vasconcelos, I. B., da Silva, T. G., Militão, G. C., Soares, T. A., Rodrigues, N. M., Rodrigues, M. O., et al. (2012). Cytotoxicity and slow release of the anti-cancer drug doxorubicin from ZIF-8. RSC Adv. 2, 9437-9442. doi: 10.1039/c2ra21087h

Vena, M. P., Jobbágy, M., and Bilmes, S. A. (2016). Microorganism mediated biosynthesis of metal chalcogenides; a powerful tool to transform toxic effluents into functional nanomaterials. Sci. Total Environ. 565, 804-810. doi: $10.1016 /$ j.scitotenv.2016.04.019

Vijayakumari, J., Raj, T. L. S., Selvi, A. A., Glenna, R., and Raja, P. (2019). A comparative study of plant mediated synthesis of silver, copper and zinc nanoparticles from tiliacora acuminata (lam.) Hook. F. and their antibacterial activity studies. Synthesis $18,19-34$.

Vissers, C., Ming, G.-L., and Song, H. (2019). Nanoparticle technology and stem cell therapy team up against neurodegenerative disorders. Adv. Drug Deliv. Rev. 148, 239-251. doi: 10.1016/j.addr.2019.02.007

Viswanathan, A., Rangasamy, J., and Biswas, R. (2019). "Functionalized antibacterial nanoparticles for controlling biofilm and intracellular infections," in Surface Modification of Nanoparticles for Targeted Drug Delivery (Cham: Springer), 183-206.

Walmsley, G. G., McArdle, A., Tevlin, R., Momeni, A., Atashroo, D., Hu, M. S., et al. (2015). Nanotechnology in bone tissue engineering. Nanomedicine 11, 1253-1263. doi: 10.1016/j.nano.2015.02.013

Wang, H.-N., Meng, X., Yang, G.-S., Wang, X.-L., Shao, K.-Z., Su, Z.-M., et al. (2011). Stepwise assembly of metal-organic framework based on a metal-organic polyhedron precursor for drug delivery. Chem. Commun. 47, 7128-7130. doi: $10.1039 / \mathrm{clcc} 11932 \mathrm{j}$

Wang, L., Hu, C., and Shao, L. (2017). The antimicrobial activity of nanoparticles: present situation and prospects for the future. Int. J. Nanomed. 12, 1227-1236. doi: $10.2147 /$ IJN.S121956

Wang, M., Zhang, T., Hu, Y., Qin, Y., and Wei, W. (2019). In situ synthesis of dicarboxylic acid functionalized upconversion nanoparticles for bioimaging applications. Chem. Photo Chem. 3, 145-150. doi: 10.1002/cptc.201800180

Wang, S., Li, J., Zhou, Z., Zhou, S., and Hu, Z. (2019). Micro-/nanoscales direct cell behavior on biomaterial surfaces. Molecules 24, 75-86. doi: 10.3390/molecules 24010075

Wang, Y., Xu, C., Chang, Y., Zhao, L., Zhang, K., Zhao, Y., et al. (2017). Ultrasmall superparamagnetic iron oxide nanoparticle for $\mathrm{T}$ 2-weighted magnetic resonance imaging. ACS Appl. Mater. Interfaces 9, 28959-28966. doi: $10.1021 /$ acsami.7b10030

Wang, Y. M., Liu, W., and Yin, X. B. (2016). Self-limiting growth nanoscale coordination polymers for fluorescence and magnetic resonance dualmodality imaging. Adv. Funct. Mater. 26, 8463-8470. doi: 10.1002/adfm.20 1602925

Wani, W. A., Baig, U., Shreaz, S., Shiekh, R. A., Iqbal, P. F., Jameel, E., et al. (2016). Recent advances in iron complexes as potential anticancer agents. New J. Chem. 40, 1063-1090. doi: 10.1039/C5NJ01449B

Wei, L.-Q., Chen, Q., Tang, L.-L., Zhuang, C., Zhu, W.-R., and Lin, N. (2016). A porous metal-organic framework with a unique hendecahedron-shaped cage: structure and controlled drug release. Dalton Trans. 45, 3694-3697. doi: $10.1039 / C 5 D T 04379 D$ 
Wu, M., Hou, P., Dong, L., Cai, L., Chen, Z., Zhao, M., and Jingjing, L. I. (2019). Manganese dioxide nanosheets: from preparation to biomedical applications. Int. J. Nanomed. 14, 4781-4800. doi: 10.2147/IJN. S207666

Xiong, J., Wang, Y., Xue, Q., and Wu, X. (2011). Synthesis of highly stable dispersions of nanosized copper particles using L-ascorbic acid. Green Chem. 13, 900-904. doi: 10.1039/c0gc00772b

Xu, P., Zeng, G. M., Huang, D. L., Feng, C. L., Hu, S., Zhao, M. H., et al. (2012). Use of iron oxide nanomaterials in wastewater treatment: a review. Sci. Total Environ. 424, 1-10. doi: 10.1016/j.scitotenv.2012.02.023

Xue, Z., Zhang, Y., Yu, W., Zhang, J., Wang, J., Wan, F., et al. (2019). Recent advances in aflatoxin B1 detection based on nanotechnology and nanomaterials-a review. Anal. Chim. Acta. 1069, 1-27. doi: 10.1016/j.aca.2019.04.032

Yamada, M., Foote, M., and Prow, T. W. (2015). Therapeutic gold, silver, and platinum nanoparticles. Wiley Interdiscip. Rev. Nanomed. Nanobiotechnol. 7, 428-445. doi: 10.1002/wnan.1322

Yaqoob, A. A., Khan, R. M. R., and Saddique, A. (2019). Review article on applications and classification of gold nanoparticles. Int. J. Res. 6, 762-768.

Yaqoob, A. A., Parveen, T., Umar, K., and Ibrahim, M. N. M. (2020a). Role of nanomaterials in the treatment of wastewater: a review. Water 12:495. doi: 10.3390/w12020495

Yaqoob, A. A., Umar, K., and Ibrahim, M. N. M. (2020b). Silver nanoparticles: various methods of synthesis, size affecting factors and their potential applications-a review. Appl. Nanosci. 10, 1-10. doi: 10.1007/s13204-020-01318-w

Young, S. W. S., Stenzel, M., and Jia-Lin, Y. (2016). Nanoparticle-siRNA: a potential cancer therapy. Crit. Rev. Oncol. Hematol. 98, 159-169. doi: 10.1016/j.critrevonc.2015.10.015

Zamani, M., Rostami, M., Aghajanzadeh, M., Manjili, H. K., Rostamizadeh, K., and Danafar, H. (2018). Mesoporous titanium dioxide@ zinc oxide-graphene oxide nanocarriers for colon-specific drug delivery. J. Mater. Sci. 53, 1634-1645. doi: $10.1007 / \mathrm{s} 10853-017-1673-6$
Zhang, Q., Lu, X., Tang, P., Zhang, D., Tian, J., and Zhong, L. (2016). Gold nanoparticle (AuNP)-based surface-enhanced Raman scattering (SERS) probe of leukemic lymphocytes. Plasmonics 11, 1361-1368. doi: 10.1007/s11468-016-0185-6

Zhang, W.-H., Hu, X.-X., and Zhang, X.-B. (2016). Dye-doped fluorescent silica nanoparticles for live cell and in vivo bioimaging. Nanomaterials 6, 81-89. doi: 10.3390/nano6050081

Zhao, L., and Ashraf, M. A. (2015). Influence of silver-hydroxyapatite nanocomposite coating on biofilm formation of joint prosthesis and its mechanism. West Indian Med. J. 64, 506-513. doi: 10.7727/wimj.2016.179

Zhong, D. C., Liao, L. Q., Deng, J. H., Chen, Q., Lian, P., and Luo, X. Z. (2014). A rare $(3,4,5)$-connected metal-organic framework featuring an unprecedented $1 \mathrm{D}+2 \mathrm{D} \rightarrow 3 \mathrm{D}$ self-interpenetrated array and an $\mathrm{O}$-atom lined pore surface: structure and controlled drug release. Chem. Commun. 50, 15807-15810. doi: 10.1039/C4CC08214A

Zhu, C., Ahmed, I., Parsons, A., Liu, J., and Liu, X. (2019). The mechanical property, degradation and cytocompatibility analysis of novel phosphate glass fiber textiles. Textile Res. J. 89, 3280-3290. doi: 10.1177/0040517518809052

Zhuang, W., Yuan, D., Li, J. R., Luo, Z., Zhou, H. C., Bashir, S., et al. (2012). Highly potent bactericidal activity of porous metal-organic frameworks. Adv. Healthcare Mater. 1, 225-238. doi: 10.1002/adhm.201100043

Conflict of Interest: The authors declare that the research was conducted in the absence of any commercial or financial relationships that could be construed as a potential conflict of interest.

Copyright (C) 2020 Yaqoob, Ahmad, Parveen, Ahmad, Oves, Ismail, Qari, Umar and Mohamad Ibrahim. This is an open-access article distributed under the terms of the Creative Commons Attribution License (CC BY). The use, distribution or reproduction in other forums is permitted, provided the original author(s) and the copyright owner(s) are credited and that the original publication in this journal is cited, in accordance with accepted academic practice. No use, distribution or reproduction is permitted which does not comply with these terms. 